\title{
Interplay between receptor tyrosine kinases and hypoxia signaling in cancer
}

\author{
Astrid A. Glück ${ }^{1,2}$, Daniel M. Aebersold ${ }^{1,2}$, Yitzhak Zimmer ${ }^{1,2^{*}}$, Michaela Medováa ${ }^{1,2^{*}}$ \\ ${ }^{1}$ Department of Radiation Oncology, Inselspital, Bern University Hospital, and University of \\ Bern, 3010, Bern, Switzerland \\ ${ }^{2}$ Department of Clinical Research, Inselspital, Bern University Hospital, and University of \\ Bern, 3010, Bern, Switzerland \\ * equal contribution
}

Corresponding author: Michaela Medová, PhD., Department of Clinical Research, Radiation Oncology, MEM-E818, Murtenstrasse 35, 3010 Bern, Switzerland. Tel.: 0041/31/6323565, Fax: 0041/31/6323297, E-mail: michaela.medova@dkf.unibe.ch

Running title: Receptor tyrosine kinases and hypoxia

Keywords: RTKs; hypoxia; HIF system; cancer; VEGF 
ARNT - aryl hydrocarbon nuclear translocator

BCRP - breast cancer resistant protein

CAD - C-terminal activation domain

CAIX - carbonic anhydrase IX

CAV1 - caveolin-1

ccRCC - clear cell renal cell carcinoma

CSC - cancer stem cells

DAG - diacylglycerol

DUSP2 - dual specificity phosphatase 2

$\mathrm{EGF}(\mathrm{R})$ - epidermal growth factor (receptor)

EMT - epithelial-mesenchymal transition

FGF(R) - fibroblast growth factor (receptor)

GAS6 - growth arrest-specific 6

GDNF - glial-derived neurotrophic factor

GTP - guanosine triphosphatase

GTPases - guanosine triphosphatases

HCC - hepatocellular carcinoma

HGF - hepatocyte growth factor

HIF - hypoxia inducible factor

HNSCC - head and neck squamous cell carcinoma

HUVECs - human umbilical vein endothelial cells

IGF(R) - insulin-like growth factor (receptor)

IR - insulin receptor

IRES - ribosome entry sites

IRS - insulin receptor substrates

MAPK - mitogen-activated protein kinase

miRNA - microRNAs

MSP - macrophage stimulating protein

mTOR - mammalian target of rapamycin

Necl-2 - Nectin-like molecule-2

NF-kB - nuclear factor-kB 
NRG-1 - Neuregulin-1

NSCLC - non-small cell lung cancer

$\operatorname{PDGF}(\mathrm{R})$ - platelet derived growth factor (receptor)

PHD - prolyl hydroxylase

PI3K - phosphatidylinositol 3-kinase

PKA - protein kinase A

$\mathrm{PKC}$ - protein kinase $\mathrm{C}$

PLC $\gamma$ - phospholipase $\mathrm{C} \gamma$

PP2A - protein phosphatase-2A

RACK1 - receptor for activated protein kinase C

RCC - renal cell carcinoma

RON - recepteur d'origine nantais

ROS - reactive oxygen species

RTK - receptors tyrosine kinase

TGF $\alpha$ - tumor growth factor $\alpha$

Top - Topoisomerase

uPA - urokinase-like plasminogen activator

UTR - untranslated region

VEGF(R) - vascular endothelial growth factor (receptor)

VHL - Von Hippel-Lindau

VSMS - vascular smooth muscle cells 


\section{Table of Contents}

1. Introduction

2. Hypoxia-induced regulation of RTKs

2.1. Induction of RTK ligands

2.2. HIF-related transcriptional activation of RTKs: MET, AXL and RON

2.3. HIF-independent regulation of ErbB, IGFR and FGFR family members under hypoxia

3. Induction of the HIF pathway through RTK signaling

3.1. ErbB family receptors

3.2. VEGFR

3.3. MET

3.4. IGFR and IR

3.5. PDGFR, FGFR and RET

4. Tentative treatment perspectives on the crossroad of HIF-RTK signaling

5. Conclusions 


\begin{abstract}
Deregulated signaling via receptor tyrosine kinase (RTK) pathways is prevalent in numerous types of human cancers and is commonly correlated with worst prognosis, resistance to various treatment modalities and increased mortality. Likewise, hypoxic tumors are often manifested by aggressive mode of growth and progression following an adaptive genetic reprograming with consequent transcriptional activation of genes encoding proteins, which support tumor survival under low oxygen-related conditions. Consequently, both the HIF system, which is the major mediator of hypoxia-related signaling, and numerous RTK systems are considered critical molecular targets in current cancer therapy. It is now evident that there is an intricate molecular crosstalk between RTKs and hypoxia-related signaling in the sense that hypoxia can activate expression of particular RTKs and/or their corresponding ligands, while some RTK systems have been shown to trigger activation of the HIF machinery. Moreover, signaling regulation of some RTK systems under hypoxic conditions has also been documented to take place in a HIF-independent manner. With this review we aim at overviewing the most current observations on that topic and highlight the importance of the potential co-drugging the HIF system along with particular relevant RTKs for better tumor growth control.
\end{abstract}




\section{Introduction}

Receptor tyrosine kinases (RTKs) are cell surface proteins responsible for a tight regulation of a broad spectrum of downstream intra-cellular processes [1]. All RTKs are similarly structured, with a ligand binding region in the extracellular domain, a single transmembrane helix and a cytoplasmic region that comprises the protein tyrosine kinase domain as well as additional carboxy-terminal and juxtamembrane regulatory regions [2]. Following growth factor binding, the extracellular region undergoes self-association, guiding the intracellular domains into a dimeric conformation, which activates their tyrosine kinase enzymatic activity. One or more tyrosines in one receptor within the dimer are transphosphorylated by a neighboring RTK. The phosphorylated receptor subsequently recruits intracellular adaptor and transducing effectors, leading to cascades of signaling events that control growth, proliferation, differentiation and migration [1-3].

Aberrant activity of RTKs is a hallmark of a wide range of human cancers and frequently correlates with poor prognosis $[4,5]$. In normal cells, activation of RTKs and downstream signaling pathways is reversible and tightly regulated, whereas in cancer cells, RTKs acquire transforming functions due to activating mutations, gene amplificationdependent or -independent overexpression and aberrant autocrine/paracrine loops [6]. Many cancers of different histotypes often harbor genetic alterations in either RTKs themselves or in transducing elements of their downstream pathways, resulting in deregulated signaling output [7, 8]. Consequently, numerous RTK systems represent attractive therapeutic targets [9] with two leading approaches that have been translated into clinically-relevant modes to inhibit their corresponding signaling: monoclonal antibodies against the receptor itself or the putative ligand and small-molecule inhibitors that block the receptor catalytic activity [10]. Although the proof of principle of RTK targeted therapy has been well documented, acquired resistance to anti-RTKs agents ultimately develops [11]. Drug resistance usually arises through point mutations within the kinase domain, gene amplification or overexpression, or through activation of downstream bypass signaling pathways [12].

Another fundamental biologic feature, which is largely involved in aggressive manifestations of tumor growth and progression, is hypoxia. Solid tumors often become hypoxic when new blood vessels associated with tumor growth develop irregularly, resulting in poor blood flow and subsequent inefficient delivery of oxygen [13]. Poor oxygenation induces a series of cellular physiologic adaptations that are largely mediated via the hypoxiainducible factors $\alpha$ (HIF- $\alpha$ 's) transcription system that sustains and fosters tumor survival [14, 15]. Mammalian HIF- $\alpha$ subunits are encoded by three distinct genes: $H I F-1 \alpha, H I F-2 \alpha$, and 
$H I F-3 \alpha$. HIF- $1 \alpha$ is the most ubiquitously expressed, whereas HIF-2 $\alpha$ and HIF-3 $\alpha$ exhibit a more restricted tissue distribution [16]. Under normoxic conditions, oxygen-dependent prolylhydroxylases covalently modify the hypoxic response subunit HIF-1 $\alpha$, converting it to a hydroxylated form, which subsequently undergoes ubiquitination by the von Hippel-Lindau (VHL) E3 ubiquitin ligase and eventual proteasome-dependent degradation [[13]. In the presence of low oxygen concentrations, prolyl-hydroxylases are inhibited, preventing HIF-1 $\alpha$ from being degraded. Hence, HIF- $1 \alpha$ accumulates in the nucleus, where it associates to the constitutively expressed HIF-1 $\beta$ subunit (also known as the aryl hydrocarbon nuclear translocator (ARNT)). This complex activates gene transcription by binding to specific HIFresponsive elements of target genes, which are activated under hypoxic conditions [17].

Under normal physiologic conditions, as during embryogenesis, hypoxia favors the generation of niches that preserve optimal conditions for the maintenance of pluripotent cells [17]. Low oxygen tension contributes to both physiologic stemness and invasive growth, traits, which when aberrantly develop in tumor cells, lead to an aggressive malignant phenotype [17].

As to signaling interplays between hypoxia and RTKs pathways, the activation of vascular endothelial growth factor receptor (VEGFR) via HIF-mediated VEGF transcriptional activation and consequent accelerated tumor angiogenesis and systemic dissemination, represents one of the first described examples in that respect [18]. In this review, we aim at discussing the far broader emerging molecular crosstalk between RTKs activity and tumor hypoxia, which are important to understand the complex mechanisms that confer aggressive manifestation of hypoxic tumors.

\section{Hypoxia-induced regulation of RTK signaling}

Numerous genes, including those encoding for RTKs and their ligands and whose expression is regulated under hypoxic conditions, either directly by HIF-1 $\alpha$ and HIF-2 $\alpha$ transcriptional activation or by distinct hypoxia-driven mechanisms, have been identified and described using expression profiling studies [19-22]. In this chapter, we will focus on RTK systems that are transcriptionally activated by HIF-1 $\alpha$ and HIF-2 $\alpha$ and we will also describe HIF-1 $\alpha$ - and HIF-2 $\alpha$-independent mechanisms that were shown to stimulate RTKs signaling under hypoxic conditions (Figure 1). 


\subsection{Induction of RTK ligands}

Low oxygen tension has been associated with elevated production of several RTK ligands. In that respect, expression of vascular endothelial growth factor-A (VEGF-A) was shown to be induced by hypoxia in most cell types [13, 23], both in vitro and in vivo [24]. The VEGF family consists of the four homodimeric members VEGF-A, VEGF-B, VEGF-C and VEGF-D that bind and activate three corresponding VEGF receptors (VEGFR-1, VEGFR-2 and VEGFR-3), which are expressed by endothelial cells and many tumor types $[25,26]$. Under hypoxic conditions, tumor cells secrete enhanced levels of VEGF family members in a paracrine fashion to stimulate proliferation and migration of endothelial cells, thereby promoting tumor-associated angiogenesis. Additionally, VEGFs can also act in an autocrine manner as survival factors for tumor cells themselves [23, 27]. HIF-1 $\alpha$ was identified for the first time to be involved in the transcriptional activation of VEGF-A in hypoxic hepatoma cells [18]. Transcriptional response of a reporter gene expression was shown to be mediated via VEGF 5'-flanking sequences, which contain a functional HIF-1 $\alpha$ binding site [18]. Later, it was discovered that the VEGF-D promoter region also contains sequences responsible for VEGF-D induction in vascular smooth muscle cells [28]. In addition to HIF-1 $\alpha$-mediated direct transcriptional activation of $V E G F$, hypoxia has been shown to promote VEGF production by additional mechanisms. In retinal microvascular cells, it was reported that hypoxia-induced adenosine release, resulting from decreased recycling by adenosine kinase, stimulates adenosine $\mathrm{A}_{2}$ receptor and activates the cAMP-dependent protein kinase A (PKA) pathway, thereby increasing VEGF mRNA and protein levels [29, 30]. Moreover, hypoxia was shown to increase kinase activity of SRC in glioma cells, which in turn induces VEGF expression [31]. Several studies reported that in addition to increased transcriptional activation, VEGF mRNA stability is enhanced under hypoxia [32-34]. The increased stability was suggested to be mediated by a hypoxia-induced complex which binds to sequences in the 3'UTR of the VEGF mRNA [32]. These mechanisms, independent of HIF-1 $\alpha$-induced transcription, play an important role in VEGF induction. In fact, even though the VEGF-C gene has not been found to harbor HIF-binding sites, hypoxia-associated VEGF-C production has been demonstrated in breast and lung carcinomas in vitro [23].

Increased production of VEGFs is also known to be induced by deregulated production of PDGF [25, 35]. This second mechanism is indirectly mediated by the HIF system, too. In breast cancer cells, it was specifically shown that HIF-1 $\alpha$ binds to a site in intron 3 of the $P D G F-B$ gene to activate its transcription [36]. The PDGF family consists of disulfide-bonded 
homodimers of A-, B-, C- and D-polypeptide chains as well as the heterodimer PDGF-AB. Binding of the PDGF isoforms to $\alpha$ - and $\beta$ - tyrosine kinase receptors (PDGFR $\alpha$ and PDGFR $\beta$ ) promotes new vessel formation [36]. Several studies reported correlations between HIF-1 $\alpha$ expression and PDGF-B in breast cancer [36] and glioma [37]. In mice bearing triple negative breast cancer orthografts, lymphangiogenesis and lymphatic metastasis were shown to be blocked by treatment with the cardiac glycoside digoxin [38], which inhibits HIF-1 $\alpha$, or by the tyrosine kinase inhibitor imatinib via PDGFR $\beta$ targeting. This suggests that breast cancer patients might benefit from treatment aiming at targeting either HIF-1 $\alpha$ or PDGFR $\beta$ alone or both together [36].

Another RTK ligand playing an important role in hypoxia-induced tumorigenesis is insulinlike growth factor 2 (IGF2), which exerts its biologic activity via binding to the insulin-like growth factor 1 receptor (IGF1R) tyrosine kinase [39]. Activation of IGF1R in tumors is very rarely caused by gene amplification or point mutations. Constitutive receptor activation is usually a consequence of increased ligand availability [40]. IGF1R is activated upon binding of IGF1 or IGF2. IGF2 is the most highly up-regulated gene in colon cancers [41], which in turn show the highest frequency of HIF1 $\alpha$ overexpression. Expression of IGF2 was shown to be induced by hypoxia in HEPG2 hepatocellular carcinoma (HCC) cells [42]. Although IGF2 lacks a defined hypoxia responsive element containing a HIF-1 binding site, it is still possible that HIF1 $\alpha$ has an indirect effect on IGF2 expression [43].

Overexpression of HIF $1 \alpha / \mathrm{HIF}-2 \alpha$ can also occur under non-hypoxic conditions. In that respect the majority of ccRCC, the most common subtype of renal cell cancer (RCC), bear biallelic-inactivating mutations of the VHL tumor suppressor gene [44]. As a consequence, $\mathrm{VHL}^{-/-}$ccRCC cells have a constitutive, oxygen-independent activation of HIF $1 \alpha / \mathrm{HIF}-2 \alpha$ [45]. Unregulated growth of these cells was reported to be promoted by activating the transforming growth factor- $\alpha$ (TGF- $\alpha$ )/EGFR pathway. It was shown that overproduction of TGF- $\alpha$ by $\mathrm{VHL}^{-/-}$ccRCC is a direct consequence of HIF activation [45]. Notably, the use of EGFR inhibitors was as efficient as reintroducing VHL for abolishing the ability of ccRCC cells to form tumors in nude mice [46-48].

\subsection{HIF-related transcriptional activation of RTKs: MET, AXL and RON}


MET is the high-affinity receptor for hepatocyte growth factor (HGF) strongly implicated in physiological as well as in pathological cell growth, proliferation, migration and is the master regulator of the embryonic 'invasive growth' morphogenetic program [17]. Notably, already more than 10 years ago, MET expression was shown to be directly induced under hypoxic environment both in vitro and in vivo experimental setups. It was shown that both MET protein and mRNA levels increase in a panel of cancer cell lines after their exposure to low oxygen tension [49]. In experimental tumors, the formation of a gradient of MET protein expression that is inversely proportional to blood vessel proximity was observed [49]. By analyzing the human MET promoter, this induction was demonstrated to be of transcriptional origin and mediated by two different HIF-1 $\alpha$ binding sites and an AP-1 site, all located in the 5'untranslated region (5'UTR) [49, 50].

On one hand, increased expression of MET alone favors receptor oligomerization and subsequent ligand-independent activation, on the other hand, overexpression of the MET receptor was shown to render tumor cells more susceptible to stimulation by HGF [15, 49]. In several cancer cell lines, hypoxia and HGF were reported to synergize in inducing invasive growth [49]. One plausible explanation for these observations relies on the fact that the activity of proteases is promoted by hypoxia [51, 52]. HGF needs to be extracellularly converted from its inactive precursor form, pro-HGF, to mature HGF by urokinase-type plasminogen activator in order to bind to MET. Hence, elevated active HGF levels in hypoxic tumor environments might be a consequence of hypoxia-stimulated increase in protease activity [51-54]. By RNA interference, it was also demonstrated using a panel of cancer cell lines that increased invasiveness occurs due to higher levels of MET [49]. Increased motility and invasion triggered by MET activity represent the manifestation of activation of a cellular genetic reprograming for escaping hypoxic environment $[15,49]$.

Further insights over the correlation between hypoxia and MET signaling has been reported in 2006 by Ide et al who reported over the impact of MET activation on cancer cells interaction with the surrounding tumor stroma [55]. In that respect, the invasiveness of PK8 pancreatic cancer cells incubated with hypoxic conditioned medium prepared from MRC5 fibroblast cells, was shown to increase under low oxygen tension. This effect was demonstrated to arise through increased MET expression in PK8 cells and HGF secretion from MRC5 cells leading to an elevation of MET phosphorylation. The removal of HGF from the conditioned medium 
reduces the invasive activity of PK8 cells, showing the relevant impact of hypoxic stimulation on pancreatic cancer as well as stromal cells [55].

Recent reports originating from our lab suggest that MET is involved in DNA repair after exposure to ionizing radiation $[56,57]$. The use of the selective small molecule MET inhibitor PHA665752 was shown to impair homologous recombination repair of DNA double strand breaks in gastric adenocarcinoma cell lines [58]. Aberrant MET expression in poorly oxygenated tumors could provide a possible explanation as why hypoxic tumors display resistance towards radiation therapy [13], providing a further rationale for MET targeting in hypoxic tumors.

Using a variety of tumor cell line models, Lee et al. found a signaling convergence of HGF and hypoxia resulting in synergistic tumor cell invasiveness [59]. Suppression of the dual specificity phosphatase 2 (DUSP2) transcript and protein levels by hypoxia-induced reactive oxygen species (ROS) was shown to promote ERK activation resulting in cellular invasiveness. The portion of ERK activation under hypoxia is independent of MET abundance or signaling and thus additive to ERK activation induced by HGF [59]. On the other hand, hypoxia-induced ROS were reported to induce diacylglycerol (DAG) generation by phospholipase $\mathrm{C} \gamma$ (PLC $\gamma$ ), leading to protein kinase $\mathrm{C}$ activation (PKC) and increased protein phosphatase-2A (PP2A) activity, thereby suppressing HGF-induced AKT activation [59]. Hypoxic AKT suppression was associated with a decrease in cell proliferation and induction of autophagy [59], playing an important role in enhancing cell viability in adverse conditions $[60,61]$. These observations show the plasticity of invasive and proliferative tumor states, which can be mediated by the convergence of hypoxia and MET signaling pathways.

In addition to the aforementioned, MET can be activated in various HGF-independent manners. In clear cell renal cell carcinomas (ccRCC) cell lines, signaling via the AXL RTK was reported to regulate lateral activation of MET through SRC. Binding of the growth arrestspecific 6 (GAS6) ligand to AXL leads to the formation of a complex between AXL and SRC [62]. Through this event, SRC is activated and phosphorylates the intracellular domain of MET receptor to release its kinase domain from a state of autoinhibition [63]. This process is particularly increased under hypoxia since HIF- $1 \alpha$ and HIF- $2 \alpha$ have been demonstrated to bind to a functional HIF binding site in the AXL promoter, leading to increased expression of AXL in ccRCC cells [62]. 
AXL has been described as an important mediator of tumor invasion and metastasis in a number of cancers [64]. Of therapeutic relevance, the invasive and metastatic phenotype of ccRCC cells in particular, has been reported to reverse by inactivation of the GAS6/AXL signalling axis using a soluble AXL decoy receptor [62]. According to analysis of primary prostate cancer lesions and bone metastases, AXL, GAS6 and HIF-1 $\alpha$ have been found to be all co-expressed in these malignant lesions [62]. Under normoxic conditions, GAS6 promotes phosphorylation and ubiquitination of AXL via interaction with the ubiquitin ligase c-CBL, leading to downregulation of AXL protein. However, hypoxia was shown to interfere with GAS6-mediated negative regulation of AXL expression in prostate cancer cell lines [65]. Hence, in a hypoxic tumor microenvironment stabilization of AXL expression may underlie driving of metastasis progression [66]. The finding that both AXL and MET are direct targets of HIF- $1 \alpha /$ HIF- $2 \alpha$ reveals a potent mechanism of hypoxic tumors to sustain malignant phenotypes [62].

Finally, the other member of the MET RTK family, the macrophage-stimulating protein receptor/Recepteur d'Origine Nantais (RON), has been shown to cross-talk with MET [67] and in parallel, several human tumor tissues show increased RON expression [68]. Interestingly, in a panel of human breast cancer cell lines, RON was reported to be transcriptionally activated through HIF-1 $\alpha$ binding to the RON promoter in which two HRE are located [69]. Additionally and following hypoxic stress, RON was suggested to translocate to the nucleus and to interact with HIF-1 $\alpha$ in urothelial cancer cells, an interaction, which requires RON's tyrosine kinase activity [70]. The RON-HIF-1 $\alpha$ complex was shown to bind to the c-JUN promoter and synergistically activate the expression of the c-JUN gene, resulting in cell proliferation, survival and migration in vitro and tumorigenicity in vivo [70]. These observations suggest RON targeting as a potential therapeutic strategy to interfere with tumorigenic effects of nuclear RON under hypoxic conditions [70].

\subsection{HIF-independent regulation of ErbB, IGFR and FGFR family members under hypoxia}

Independently of direct HIF-1 $\alpha / \mathrm{HIF}-2 \alpha$-driven transcriptional activation, hypoxia exerts a strong impact on members of the ErbB family RTKs that consists of EGFR/ErbB1, HER2 
/ErbB2, HER3/ErbB3 and HER4/ErbB4 [71] whose aberrant activation by EGF family of growth factors is strongly associated with tumorigenesis, invasion and metastasis [72] Deregulated activity of ErbB receptors due to gene amplification, overexpression or mutations in numerous types of human cancers is tightly associated with poor prognosis and resistance to various treatment modalities [73-75].

Tumor hypoxia and EGFR expression have been found to correlate in a series of resected nonsmall cell lung cancer (NSCLC) tumors [76]. Hypoxia and HIF-2 $\alpha$ activation were specifically shown to induce EGFR overexpression by increasing EGFR mRNA translation in NSCLC cancer cell lines [76]. Mechanistically, HIF-2 $\alpha$ activation could either directly induce the expression of an activator of EGFR translation or inhibit a negative regulator of receptor synthesis. Following treatment with the EGFR inhibitors AG1478 [77] and PD153035 [78], an $\mathrm{IC}_{50}$ increase proportional to elevated EGFR levels was observed in HIF-2 $\alpha$-expressing cells. In order to clinically compensate constitutive receptor production, continuous administration of higher drug concentrations would be required [79]. Hence, EGFR upregulation may be circumvented by inhibition of HIF- $2 \alpha$ using the topoisomerase II inhibitor etoposide $[79,80]$.

In addition, EGFR activity is affected by hypoxia through another mechanism, which involves also HER4. Hypoxia-induced activation of HIF-1 $\alpha$ and HIF-2 $\alpha$ was reported to prolong EGFR [81] and HER4 [82] signaling in ccRCC and mammary carcinoma, respectively. Using cell line models, it was demonstrated that this effect arises through a delaying endocytosismediated deactivation of the receptors [81, 83]. Endocytosis consists of a sequence of early and late endosomal fusion events mediated by RAB proteins, a group of RAS-like small guanosine triphosphatases (GTPases) [84], which lead to degradation of internalized receptors in lysosomes. The best studied mediator of early endosome fusion is RAB5 [85]. ccRCC tumors with strong hypoxic signatures were shown to have reduced expression of rabaptin-5, a critical effector of RAB5. Consistent with this finding, rababtin-5 mRNA and protein levels were reported to inversely correlate with HIF status in renal oncocytomas and breast cancer specimens [81].

Apart of this mechanism, Wang et al. showed caveolin-1 (CAV1) to promote ligandindependent activation of EGFR in hypoxic ccRCC cells [86]. CAV1 is a major structural component of caveolae, which are specialized lipid raft microdomains on the cell membrane 
[87]. CAV1 is a direct transcriptional target of HIF- $1 \alpha$ and HIF-2 $\alpha$ and its elevated expression has been associated with larger tumor size, grade and stage as well as resistance to conventional therapies and poor prognosis. Under hypoxia, the formation of caveolae increases and some fraction of EGFR in the fluid of cell membrane milieu localizes there. The substantially smaller surface area of caveolae relative to the plasma membrane permits ligandindependent activation of EGFR [86]. This mechanism bypasses the requirement for ligand engagement to initiate receptor activation when ligand availability may be limited [86].

In non-transformed cells, signaling by ErbB family receptors is tightly regulated through specific endogenous mechanisms. HER2-catalyzed tyrosine phosphorylation of HER3 was shown to be inhibited by the immunoglobuline-like cell adhesion molecule Nectin-like molecule-2 (Necl-2) [88]. This protein plays important roles in a variety of cellular functions and regulates a wide range of events from normal development to tumorigenesis [72]. Through its mediated inhibition of HER2/HER3 signaling, Necl-2 serves as a tumor suppressor in many types of cancers [89]. In colon cancer cells, Necl-2 protein levels were found to decline under hypoxic conditions. Consistent with this finding, hypoxia was shown to increase HER2/HER3 signaling in these cells [72]. Hypoxia down-regulates Necl-2 in a manner that is independent of mRNA transcription and HIF-1 $\alpha$. Although enhanced expression of many hypoxia induced proteins is mediated by HIF-1 $\alpha$ or alternatively by nuclear factor- $\kappa \mathrm{B}(\mathrm{NF}-\kappa \mathrm{B})[90,91]$, it is not well characterized yet by which factor or protein complex hypoxia-induced reduction of Necl-2 is mediated [72].

To date, discovery and development of therapies targeting ErbB receptors have improved treatment outcome for many cancer patients. However, due to the development of resistance mechanisms to these drugs, current treatment strategies experience challenging limitations [71]. Following treatment of NSCLC cells that harbor activating EGFR mutations (exon 19 deletion and L858R) by a selective EGFR inhibitor gefitinib, a small fraction of cells that express stem cell markers are reported to survive [92]. Cancer stem cells (CSCs) are maintained in a quiescent state, which is considered to render them more refractory to anticancer drugs, potentially enabling tumor relapse [93, 94]. Hypoxic microenvironment was reported to be an important stem cell niche that favours CSCs survival $[92,95]$. For example, hypoxia was shown to increase the population of gefitinib-resistant CSCs by activation of IGF1R [92]. Dallas et al suggested that IGF1R plays a critical role in the persistence of CSCs, as expression of the stem cell markers CD133 and CD44 is linked to increased 
phosphorylated and total IGF1R in chemoresistant colon cancer cells [96]. Hypoxia-induced activation of IGF1R might be mediated by HIF-1 $\alpha$ as the use of the nitric oxide-guanylate cyclase activator YC-1 [97], which downregulates HIF-1 $\alpha$, was shown to suppress receptor signaling. Targeting IGF1R signaling has been suggested to be a promising strategy for overcoming therapy resistance in tumors with activating EGFR mutatios induced by CSCs and hypoxia [92].

With respect to aspects related to regulation of gene expression, hypoxia has been shown to modulate expression of various microRNAs (miRNAs) [98]. miRNAs are small, single stranded RNA molecules that bind target mRNAs resulting in suppression of protein translation and/or cleavage of the corresponding mRNA [99, 100]. In normal human urothelial cell lines, miR-100 was shown to target fibroblast growth factor receptor 3 (FGFR3) and in malignant urothelial patient samples, expression of miR-100 was observed to negatively correlate with FGFR3 mRNA [101]. FGFR3 is one of four members of the FGFR family of RTKs that functions as cell surface receptor for FGF1, FGF2, FGF4, FGF9 and FGF18 [102]. By employing RT4, RT112 and T24 bladder cancer cell lines, Blick et al have reported that miR-100 expression is suppressed under hypoxic conditions [98] and in turn, hypoxia was shown to increase FGFR3 mRNA levels [98]. Additionally, and according to analysis of a breast cancer patient cohort by Buffa et al in 2011, expression of miR-100 negatively correlates with tumor hypoxia [103]. These findings suggest that hypoxia-related miR-100 levels decrease may represent a general mechanism, which may apply for different tumor types. HIF-1 $\alpha$ seems also to play a role in the described negative regulation of this particular tumor suppressor miRNA as its knockdown suppresses FGFR3 levels in hypoxic conditions. However, the detailed molecular mechanisms have yet to be defined, as no HIF$1 \alpha$-binding sites have been found in the FGFR3 promoter and hypoxic suppression of miR100 is not necessarily reversed by HIF-1 $\alpha$ knockdown [98].

\section{Induction of the HIF pathway through RTK signaling}

This section focuses on observations demonstrating activation of the HIF pathway by various mechanisms, which are triggered via signaling by RTK systems (summarized in Figure 2). 


\subsection{ErbB family receptors}

Signaling by EGFR has been shown to increase the level of HIF-1 $\alpha$ in a variety of cancer cell types, including prostate cancer, head and neck squamous cell carcinoma (HNSCC), NSCLC and breast cancer [104-107]. Additionally, various studies reported that EGFR activity upregulates HIF-1 $\alpha$ also under normoxic conditions [104, 107-110], however, there are controversial data aiming to explain as how this event is mediated. On one hand, few studies indicate that EGF increases both HIF-1 $\alpha$ mRNA and protein levels [111]. On the other hand, different studies report that EGFR signaling leads to increased protein translation without obvious changes in the mRNA level [112]. Thus, the involvement of this RTK in the regulation of HIF-1 $\alpha$ seems to be cell-type and cancer-type specific. Similar to other RTKs, EGFR activation triggers multiple signal transduction pathways, including the phosphatidylinositol 3-kinase (PI3K)/AKT pathway [113] and the RAS/RAF/mitogenactivated protein kinase (MAPK) pathway [114]. Besides oxygen, ROS and particular Krebs cycle metabolites such as fumarate and succinate [115] have also been demonstrated to regulate prolyl-hydroxylase activity-mediating HIF-1 $\alpha$ stabilization under normoxic conditions [107, 116]. $\mathrm{H}_{2} \mathrm{O}_{2}$ has been shown to induce EGF-stimulated activation of $\mathrm{PI} 3 \mathrm{~K} / A K T$ signaling in ovarian cancer cells. Increasing evidence shows that $\mathrm{H}_{2} \mathrm{O}_{2}$ production mediates, at least in part, EGF-induced HIF-1 $\alpha$ expression in this cancer type [111]. Indeed, it has been frequently reported that PI3K/AKT signaling is involved in induced HIF-1 $\alpha$ protein expression [104, 105, 117]. A more limited number of studies has examined the impact of MAPK signaling on HIF-1 $\alpha$ expression. Some reports suggest that inhibition of the MAPK pathway does not alter EGFR-induced expression of HIF-1 $\alpha$ [112], whereas others reported that inhibition of MAPK reduces basal HIF-1 $\alpha$ activity through potential phosphorylation events [107].

Apart of EGFR, HER2 plays also an important role in the regulation of HIF-1 $\alpha$. Enhanced activity of HER2 occurs in approximately one third of breast tumors and correlates with higher tumor grade, resistances to treatment and decreased rates of patient survival [118, 119]. HER2 undergoes heterodimerization with the ErbB family members HER3 and HER4, which bind heregulin among a subset of stroma-derived growth factors [120]. HER2 overexpression or heregulin stimulation have been shown to induce VEGF mRNA and protein expression $[121,122]$. The use of a specific neutralizing monoclonal antibody against HER2 (4D5) in the 
treatment of breast cancer cells results in a dose-dependent inhibition of VEGF expression [123]. It has been demonstrated that HER2 signaling in normoxic cells promotes transcriptional activation of the VEGF gene via HIF-1 $\alpha$ and that this transcriptional activity is dependent on PI3K/AKT/mTOR signaling [110]. While hypoxia increases HIF-1 $\alpha$ protein stability and specific transcriptional activity [124], heregulin/HER2 signaling induces synthesis of HIF-1 $\alpha$ protein, such that a combination of hypoxia and HER2 overexpression synergistically increases HIF-1 $\alpha$ target genes expression [110]. Normoxic expression of HIF$1 \alpha$ was reported to mediate HER2 effects on resistance to aromatase inhibitors in breast cancer cells [125]. Aromatase inhibitors reduce circulating levels of estrogen and are clinically used to treat breast cancer [126]. Resistance to these agents arises following a switch from dependence on estrogen receptor signaling to dependence on HER2 signaling [127]. HIF-1 $\alpha$ orchestrates the activation of target genes involved in processes that promote resistance to aromatase inhibitors. In particular, breast cancer resistant protein (BCRP), a HIF$1 \alpha$ target gene, was reported to play a role in resistance to these agents and in maintenance of stem cell characteristics in breast cancer. Hence, inhibition of HIF-1 $\alpha$ expression and activity has been suggested to extend tumor cells sensitivity to aromatase inhibitors and averting recurrence and metastasis [125].

In contrast to the other ErbB family members, HER4 has been suggested to positively impact HIF-1 $\alpha$ signaling via a substantially different mechanism. In mammary carcinoma cells, HER4 activated by binding of neuregulin-1 was shown to promote accumulation of HIF-1 $\alpha$ in normoxia, while HER4 signaling resulted in a further increase of HIF-1 $\alpha$ protein under hypoxic conditions [128]. This corresponding accumulation was shown to result from promotion of HIF-1 $\alpha$ protein stability in a VHL- and prolyl-hydroxylase-independent manner [128]. Proteasomal degradation of HIF-1 $\alpha$ was reported to take place by interaction with the receptor for activated protein kinase C/RACK1 in an oxygen-independent way [129]. Thus, when HER4 is activated, a soluble HER4 intracellular domain is proteolytically released and it translocates to the nucleus, where it can directly interact with nuclear HIF-1 $\alpha$, leading to suppression of RACK1-dependent proteasomal degradation of HIF-1 $\alpha$ [128]. Notably, and in support of the role of HER4 in HIF-1 $\alpha$ regulation, HIF-1 $\alpha$ expression levels in vivo were found to be higher in mammary glands of wild-type mice compared to glands of mice in which HER4 was ablated [128]. Moreover, HER4 expression was reported to correlate with the expression of HIF-1 $\alpha$-regulated genes in a number of human normal and cancer tissue samples [128]. 


\subsection{VEGFR}

VEGFR signaling has been shown to affect HIF proteins expression and phosphorylation in various cell types. Recent studies using neuroblastoma cells indicated that VEGF-induced activation of VEGFR-1 leads to increase of both HIF-1 $\alpha$ and HIF-2 $\alpha$ protein levels [130]. In clinical neuroblastoma specimens, HIF-2 $\alpha$ protein levels positively correlate with VEGF expression and poor patient outcome [131]. Additionally, HIF-1 $\alpha$ phosphorylation was shown to decrease following inhibition of VEGF/VEGFR-1 autocrine signaling. In this loop, VEGFR-1 signaling activates ERK1/2 in new arisen hypoxia. ERK1/2 in turn activates HIF$1 \alpha$ which up-regulates VEGF and VEGFR-1, leading to further stimulation of ERK1/2. VEGFR-1-expressing neuroblastoma cells show hypoxia-mediated resistance to several chemotherapeutic agents, including etoposide, doxorubicin, melphalan and cyclophosphamide [132]. VEGFR-1 activity was associated with increase of bcl-2, a significant antiapoptotic protein, and FGF, a strong angiogenic factor. Hence, such an autocrine VEGF/VEGFR-1- HIF loop is likely to contribute to cell survival, drug resistance and angiogenesis during hypoxia [132].

In a similar fashion, in endothelial cells, an interaction between a hypoxia-driven VEGF/VEGFR-2 autocrine loop and HIF-1 $\alpha$ has also been demonstrated [133]. VEGFR-2 has been defined as the dominant signaling receptor in endothelial cells. In contrast, VEGFR-1 has weak tyrosine kinase activity but a 10-fold higher binding affinity for VEGF. This led to a suggestion that VEGFR-1 sequesters VEGF from signaling through VEGFR-2 and thus acts as a decoy receptor [134]. However, recent studies in several tumor cells indicate that VEGF/VEGFR-1 possesses autocrine survival activity as well [135-137].

\subsection{MET}

An additional mechanism by which HIF-1 $\alpha$ confers oncogenic activity to EGFR is by an EGFR-related activation of MET expression. EGFR-activating mutations have been found to associate with elevated levels of MET in both NSCLC transgenic murine models and clinical samples [138]. Using NSCLC cell lines, Xu et al have shown that the HIF-1 $\alpha$ /MET axis plays 
an important role in regulating invasiveness induced not only by hypoxia but also by EGFR signaling. As mentioned in section 1.1., hypoxia is a regulator of HGF, presumably through HIF- $1 \alpha$ activity [55]. In this respect, Xu et al suggested that EGFR-activating mutations could promote production of HGF through HIF- $1 \alpha$ and thus EGFR/HIF-1 $\alpha$ activation may not only regulate MET levels, but also have an impact on MET signal transduction [138].

In addition, HGF-induced MET activity in hepatoma cells was reported to increase HIF-1 $\alpha$ mRNA and protein levels as well as activation of HIF-1 $\alpha$ DNA-binding and target genes expression [139]. Blockade of the PI3K pathway was shown to abrogate the HIF-1 $\alpha$ DNAbinding activity, but inhibition of the MAPK pathway in this respect had no effect. Similarly to what has been reported concerning the EGFR, it is likely that ROS produced during HGFtriggered signaling play a critical role [139]. ROS are recognized as stress-associated stimuli, which can activate the NF- $\mathrm{BB}$ transcription factor. Indeed, in different cancer cell lines, it has been reported that transduction pathways triggered by the HGF/MET binding lead to activation of $\mathrm{NF}-\kappa \mathrm{B}$, which is able to regulate expression of HIF-1 $\alpha$ [140]. Based on luciferase reporter assays, the regulation by $\mathrm{NF}-\kappa \mathrm{B}$ seems to be mediated by binding to the 5'UTR region of the HIF-1 $\alpha$ mRNA [140].

Abrogating the HGF/MET signaling axis using decorin, a small leucine-rich proteoglycan, was reported to reduce HIF-1 $\alpha$ and VEGF-A expression in breast carcinoma cells, thereby repressing VEGF-A-mediated angiogenesis under normoxia. This effect has been attributed to MET inhibition as suppression of MET expression using siRNA evoked a similar reduction of VEGF-A protein levels [141]. However, decorin is known to induce down-regulation of multiple RTKs apart of the MET receptor, including EGFR [142-144] and other ErbB family members [145]. It antagonizes these RTKs by receptor internalization via caveolar-mediated endocytosis [146] confirming once again that EGFR as well as MET signaling both seem to have a strong impact on the HIF-1 $\alpha$ transcription factor activity.

\subsection{IGFR1 and IR}

IGF1R signaling, similarly to HER2 activation, was shown to mediate resistance to aromatase inhibitors [127]. In glioblastoma cells, IGF1R activation by stimulation either with IGF1 or IGF2 was shown to give rise to HIF-1 $\alpha$ protein expression, HIF-1 $\alpha$ DNA-binding activity and 
transcriptional activation of its downstream target genes [147]. In colon cancer cells, the increased HIF-1 $\alpha$ expression following IGF1 treatment was shown to be triggered by stimulation of HIF-1 $\alpha$ protein synthesis [40]. As previously mentioned, IGF2 is among the target genes that are transactivated by HIF-1 $\alpha$, thereby providing a link in an autocrine selfamplifying loop [147]. In contrast to heregulin-stimulated breast cancer cells, enhanced HIF$1 \alpha$ protein synthesis in colon cancer cells is dependent rather on STAT3 than on mTOR. For IGF1R signaling, PI3K/AKT/mTOR activation requires intracellular recruitment of insulin receptor substrates (IRS) 1 and 2 to the activated receptor [148]. As mTOR is known to downregulate IRS1/2 [149], activation of this pathway would have a self-inhibitory effect on HIF-1 $\alpha$ synthesis. In many tumor types, the JAK/STAT pathway has been defined as important mediator of IGF-dependent signaling [150]. STAT3 can be recruited by IGF1R independently of IRS1/2 and subsequently modulate expression of AKT [151]. Particularly in hypoxic tumors bearing autocrine regulation of the IGF-HIF-1 $\alpha$ axis, pharmacological inhibition of IGFR1 or STAT3 may provide a significant therapeutic benefit. Indeed, HIF-1 $\alpha$ synthesis was shown to be abrogated in glioblastoma cells following exposure to the selective IGF1R inhibitor NVP-AEW541 [147].

IGF1/2 have many signaling effectors and cellular responses that are shared with insulin and the insulin receptor (IR) [152]. Insulin is a central regulator of metabolic pathways associated with energy storage and utilization [153]. Both hypoxia and insulin increase the level of glucose transporters and glycolytic enzymes [154, 155], contributing to increased glycolysis [153]. Emerging evidence suggests that binding of insulin to IR induces HIF-1 $\alpha$ protein translation through activation of the PI3K/AKT/mTOR pathway in retinal epithelial cells [156]. mTOR seems to be involved in the insulin action on HIF-1 $\alpha$ regulation only partly, as inhibition of mTOR does not completely abolish HIF-1 $\alpha$ expression. This finding suggests that both an AKT-dependent/mTOR-independent and an AKT/mTOR-dependent pathway may be involved in insulin-induced HIF-1 $\alpha$-translation [156]. HIF-1 $\alpha$ expressed through insulin stimulation increasingly activates transcription of VEGF [156]. In fact, intraocular VEGF levels have been observed to be increased in diabetic patients suffering from proliferative retinopathy due to hyperinsulinemia induced by insulin treatment [157].

\subsection{PDGFR, FGFR and RET}


As mentioned in section 1.1., PDGF can increase transcription and secretion of VEGF by PDGFR-expressing endothelial cells. Elevated PDGFR levels have been commonly observed in neovascular endothelial cells during tumorigenesis but the downstream molecular mechanisms by which PDGF transduces its signals via PDGFR to mediate VEGF secretion were not known [158]. In a recent study using vascular smooth muscle cells (VSMS), Richard et al reported that PDGF can increase HIF-1 $\alpha$ protein to levels that are more elevated than in hypoxia, which may play a major role in VEGF production [159]. On the other hand, PDGF leads only to a small or no increase of HIF-1 $\alpha$ levels in fibroblasts and in endothelial cells, respectively [159], rendering this effect to be cell-specific. As for other RTK pathways, it was reported that the increase of HIF-1 $\alpha$ protein level is mediated through the production of ROS [159]. This mechanism emphasizes the importance of up-regulation of PDGF or its receptors in regulating of the angiogenic switch in early stages of tumor development, in contrast to hypoxia, being a stimulus for neovascularization in an already established tumor [158].

Other major angiogenic inducers, the FGFRs, were also found to be involved in the regulation of the hypoxic pathway [160]. Cord formation of human umbilical vein endothelial cells (HUVECs) was shown to depend on HIF-1 $\alpha$ activity and on the induction of FGFRs. Knockdown of either HIF-1 $\alpha$ or FGF2 indicated that FGF2 and HIF-1 $\alpha$ reciprocally regulate their expression [161]. These findings suggest the existence of a crosstalk between HIF-1 $\alpha$ and FGF2 that mediates an autocrine pathway in hypoxia [161].

In glioblastoma, FGF2 seems to play an important role in the response to ionizing radiation. Preclinical treatment with SSR12819E, the first-in-class compound able to inhibit FGF2 binding to FGFR-1 [162] was reported to decrease glioblastoma cells radioresistance both in vitro and in vivo [163]. The radiosensitizing effect of SSR12819E might be a consequence of FGFR-1 endocytosis and subsequent degradation. At the same time, inhibition of the small GTPase RHOB, usually induced by FGF2 stimulation, occurs [160]. Abrogating RHOB activity enhances proteasome-dependent degradation of HIF-1 $\alpha$ [163], showing that regulation of HIF-1 $\alpha$ by FGFR-1 could be involved in resistance to radiation therapy.

The increased resistance of glioblastoma cells to ionizing radiation is potentially mediated through transactivation of specific target genes by HIF-1 $\alpha$. One direct target gene whose expression significantly correlates in many tumor types with poor prognosis and resistance to chemotherapy in general is carbonic anhydrase IX (CAIX) [164], an enzyme which promotes 
conversion of carbon dioxide to bicarbonate ions and protons. CAIX plays an important role in $\mathrm{pH}$ regulation, a crucial step for survival of tumor cells in hypoxia and acidosis [165]. Its expression has been found almost exclusively in tumors and it is considered as one of the main intrinsic markers of tumor hypoxia $[164,166]$. Recently, CAIX expression was reported to correlate with overexpression of the RET RTK in medullary thyroid carcinoma. Overexpression of RET, which mimics ligand-independent activation often occurring in advanced medullary thyroid carcinomas, increases CAIX promoter activity induced by HIF$1 \alpha$ in a cellular model [167]. It is suggested that both PI3K and MAPK pathways can mediate this phenomenon [167]. The crosstalk between RET and HIF-1 $\alpha$ has been described also in neuroblastoma cells, where activation of RET induced by its ligand GDNF increases HIF-1 $\alpha$ protein levels [130]. In turn, expression of GDNF was reported to be increased in hypoxic rat astrocytes [168]. This ligand-dependent stimulation may create a positive feedback loop in the hypoxic pathway.

\section{Tentative treatment perspectives on the crossroad of HIF-RTK signaling}

There are numerous reviews focusing on targeting HIF-1 as well as RTK systems in cancer. In this section, we are specifically aiming at discussing strategies, which might be relevant for the crosstalk between hypoxia and RTKs activated pathways.

As signaling by various RTKs was shown to elevate HIF- $1 \alpha$ as well as HIF- $2 \alpha$ protein levels and similarly, the activity of these two transcription factors induces signaling by several RTKs, combining HIF inhibitors with RTK targeting agents may proof as an effective anticancer treatment. Such combined modalities may allow lower doses of each individual drug, thereby reducing the probability of off-targeting toxic effects and also reduce the likelihood of selecting for drug resistant cancer cells. Many of the currently available molecules targeting the HIF system show preferential activity against HIF-1 $\alpha$, with less or no effect on HIF-2 $\alpha$ [169]. Interestingly, these agents, such as digoxin, etoposide or YC-1, have been originally designed to act on cellular targets distinct than HIF- $1 \alpha$, and HIF- $1 \alpha$ inhibition was observed as a secondary effect [169]. Here we will discuss the mechanisms of action of these compounds and the impact of their use on the HIF-RTK systems crosstalk.

Digoxin belongs to a class of cardiac glycosides used to treat congestive heart failure and arrhythmias. Cardiac glycosides bind to the $\alpha$-subunit of the sodium pump (Na+/K+ ATPase) 
and inhibit its activity [170]. The sodium pump is most abundantly expressed in iontransporting epithelia and is responsible for translocating sodium and potassium ions across the cell membrane utilizing ATP as the driving force [170]. Studies conducted over the last decade suggest that cardiac glycosides may be successful as anti-cancer agents [170, 171]. Digoxin and other members of this class were shown to inhibit HIF-1 $\alpha$ protein synthesis and expression of HIF-1 $\alpha$ target genes in several cancer cells [172]. However, the mechanism by which these effects are mediated remains unclear. It was suggested that cardiac glycosides promote sequestration of HIF-1 $\alpha$ mRNA in stress granules [172], which are usually formed following exposure of cancer cells to hypoxia and contain mRNAs which are not translated until the cells are reoxygenated [173].

In general, digoxin was found to increase tumor latency and inhibit tumor xenograft growth in mice. As discussed in detail in section 2.1., in mice bearing breast cancer orthografts, digoxin was reported to block lymphangiogenesis and lymphatic metastases to a similar extent as PDGFR $\beta$ inhibition by imatinib [36]. Interestingly, xenografts derived from cells with HIF-1 $\alpha$ enforced expression were resistant to the anti-tumor effect of digoxin, showing that HIF-1 $\alpha$ is the critical target of digoxin for cancer therapy [172]. Currently, digoxin is evaluated in a phase 2 clinical trial intended for newly diagnosed operable breast cancer [174].

Another class of potential HIF-1 $\alpha$-targeting agents is represented by topoisomerase (Top) inhibitors. Top inhibitors were originally designed and are being primarily used to induce cellular DNA damage [175]. Later on, both Top I and II inhibitors were shown to modulate HIF-1 $\alpha$ synthesis. Topotecan, a representative member of Top I inhibitors [176, 177], has been the first agent from this class of inhibitors to be tested in humans for the purpose of inhibiting HIF-1 $\alpha$ synthesis [178]. Currently, topotecan is approved as HIF antagonist for the treatment of metastatic ovarian cancer, small cell lung cancer and cervical cancer [174]. In addition, the Top II inhibitor etoposide was reported to circumvent EGFR up-regulation in HIF-2 $\alpha$-overexpressing cancer cells (discussed in 2.3.) [79, 80], being eventually one of the few agents capable to target not only HIF-1 $\alpha$, but also HIF-2 $\alpha$. In NSCLC cells, topotecan and etoposide were both shown to inhibit the accumulation of hypoxia-induced HIF-1 $\alpha$ protein through the PI3K-AKT pathway and proteasomal degradation [175]. This inhibitory effect seems to be dependent on the expression of Tops, as silencing of these proteins abrogates the inhibition of HIF-1 $\alpha$ accumulation [175] but the exact mechanism of how expression of Tops affects HIF-1 $\alpha$ metabolism has not been elucidated yet [175]. 
YC-1 (3-[5'hydroxymethyl-2'-furyl]-1-benzylindazole), a nitric oxide-independent activator of soluble guanylyl cyclase, was originally developed as a therapeutic agent for circulation disorders. YC-1 inhibits platelet aggregation and vascular contraction by activating soluble guanylyl cyclase $[179,180]$. Interestingly, YC-1 was reported to downregulate HIF-1 $\alpha$ and to suppress IGF1R signaling, thus overcoming gefitinib resistance in NSCLC cells expressing activating EGFR mutations (2.3.) [92]. Moreover, YC-1 was shown to block HIF-1 $\alpha$ expression at the posttranscriptional level and consequently to inhibit transcription factor activity of HIF-1 $\alpha$ in vitro [181]. It was suggested that YC-1 prevents HIF-1 $\alpha$ translation by

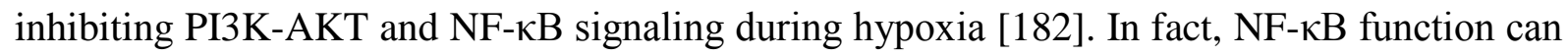
be stimulated by phosphorylation through AKT [183] and, as aforementioned, activated NF$\kappa \mathrm{B}$ was found to upregulate HIF-1 $\alpha$ expression [140]. Tumors from YC-1-treated mice are generally significantly smaller, express lower levels of HIF-1 $\alpha$ and are less vascularized, regardless of tumor type [181]. However, as potential use of YC-1 is likely to result in increased bleeding time and hypotension at dosages relevant for cancer chemotherapy, this drug has not been tested in clinical trials to date [174]. Potential side effects of YC-1 have to be carefully evaluated before this compound or its eventual analogues could be developed as new anticancer agents [181].

In addition to these pharmacological agents, HIF-1 $\alpha$ levels were reported to be affected by therapeutic interventions that perturb signaling cascades that are activated by RTKs. This category of compounds include primarily mTOR inhibitors as temsirolimus (CCI-779) and everolimus (RAD001), which are clinically approved drugs [174]. Upon activation of the PI3K/AKT pathway, mTOR phosphorylates eIF4F-binding proteins that serve as negative regulators of the eIF4F translation initiation complex, resulting in its release from inhibition with concomitant translation of proteins involved in cell cycle progression, in addition to increased translation of $\operatorname{HIF}[184,185]$. Among the first preclinical studies that reported observations along this line is a 2006 work by Del Bufalo et al who showed that in BT474, a human breast cancer line that harbors HER2 amplification, temsirolimus inhibited VEGF production under both normoxic and hypoxic conditions through inhibition of HIF-1 $\alpha$ expression and transcriptional activation [186]. In a subsequent study, Wangpaichitr et al reported that HIF-1 $\alpha$ down-regulation by temsirolimus coincided with increased toxicity towards the glycolysis inhibitor 2-deoxy-d-glucose in lung cancer cells [187]. Likewise, treatment with everolimus was reported to repress expression of HIF-1 $\alpha$ and its transcriptional target VEGF in ovarian clear cell adenocarcinoma models [188]. Furthermore, it was shown that the use of everolimus reversed a prostatic intraepithelial neoplasia phenotype in mice by 
decreasing not only HIF-1 $\alpha$ protein, but also mRNA level as well as expression of HIF-1 $\alpha$ target genes encoding enzymes essential for glycolysis [189]. It is important however to emphasize that these reported observations so far have been detected in preclinical models. The impact level of mTOR inhibitors on HIF-1 $\alpha$ orchestrated metabolism in patients needs yet to be determined.

In addition to HIF- $1 \alpha$ inhibition, gene products regulated by HIF- $1 \alpha$ that activate RTKs signaling can be considered as targets. In this respect, the use of the approved monoclonal antibody bevacizumab which blocks VEGF-A [190] has been tested in combination with bortezomib in a phase 1 clinical trial [190]. Bortezomib is a proteasomal inhibitor, which, as other agents belonging to this class, increases overall HIF-1 $\alpha$ levels, but inhibits HIF function by targeting its C-terminal activation domain (CAD) [191]. According to the aforementioned clinical trial, bevacizumab and bortezomib are well-tolerated and have achieved an inhibition of angiogenic activity in patients with previously treated advanced malignancies [190].

In summary, as emerging evidence suggests that inhibition of a single RTK overexpressed in hypoxia may fail due to the involvement of HIF-1 $\alpha$-dependent induction of effectors implicated in tumor progression, combination treatment with HIF inhibitors emerges as an important potential strategy for improving the efficacy of RTK targeting agents, particularly in cases when hypoxic regions within tumors are evident.

\section{Conclusions}

Solid tumors develop hypoxic regions primarily due to aberrant neovascularization with consequent poor blood supply. Lesions with deprived oxygenation may manifest particular aggressive phenotypes due to series of cellular adaptations that sustain and eventually foster tumor local invasion and systemic dissemination. A major common feature of hypoxic tumors is the activation of the HIF system, leading essentially to upregulation of a battery of genes encoding for proteins that support cellular survival in low-oxygen conditions.

Dysregulation of RTK signaling is an abundant feature of a wide range of cancers and is generally associated with increased cell proliferation, motility and resistance to cell death signals. As previously discussed, under low oxygen tension, signaling by various RTK systems is considerably amplified. This hypoxia-stimulated increase in RTK signaling is 
mediated through several distinct mechanisms including transcriptional activation, enhanced mRNA stability, which is associated with increased translation of some RTKs or of their ligands, delayed RTK endocytosis as well as downregulation of proteins and miRNAs, which negatively regulate RTK expression and signaling. Likewise, signaling by various RTK systems was found to activate the HIF system, by inducing transcription or translation of HIF$1 \alpha /$ HIF- $2 \alpha$, by increasing the protein stability or by enhancing the DNA-binding and transactivation ability of HIF transcription factors.

In summary, although the current knowledge on RTKs signaling under hypoxic conditions and the impact of RTKs signaling on HIF-associated pathways is continuously expanding, the detailed molecular mechanisms underlying many of the observations described within this review remain largely unknown. However, this emerging intricate molecular crosstalk between RTK systems and hypoxic pathways, each correlated with bad prognosis and increased patient mortality, strongly supports the rationale of combining HIF inhibitors with RTK targeting for the treatment of various solid cancers. This strategy could particularly turn out to be effective in suppressing aberrant RTKs signaling axes, which are dependent on activation via the HIF transcriptional machinery. 
Table 1: Mechanisms of RTK activation through hypoxia in experimental tumor cellular models

\begin{tabular}{|c|c|c|}
\hline Cell type & RTK / ligands & mechanism \\
\hline $\begin{array}{l}\text { SiHa cervix squamous cell } \\
\text { carcinoma cells, HepG2 } \\
\text { hepatocellular carcinoma } \\
\text { cells, A549 lung carcinoma } \\
\text { cells, MLP-29 mouse liver } \\
\text { progenitor cells, PK8 } \\
\text { pancreatic cancer cells }\end{array}$ & MET & Transcriptional activation by HIF- $1 \alpha^{[49,55]}$ \\
\hline $\begin{array}{l}\text { SN12L1 clear cell renal cell } \\
\text { carcinoma (ccRCC) cells }\end{array}$ & MET & $\begin{array}{l}\text { AXL signalling mediated lateral activation by } \\
\text { SRC }{ }^{[62]}\end{array}$ \\
\hline $\begin{array}{l}\text { RCC4 ccRCC cells, 786-0 } \\
\text { ccRCC cells, HepG2 } \\
\text { hepatocellular carcinoma } \\
\text { cells, Hep3B hepatocellular } \\
\text { carcinoma cells }\end{array}$ & AXL & $\begin{array}{l}\text { Transcriptional activation by HIF- } 1 \alpha \text { and HIF- } 2 \alpha \\
\text { [62] }\end{array}$ \\
\hline $\begin{array}{l}\text { HLEC lens epithelial cells, } \\
\text { PC3 and Du-145 prostate } \\
\text { cancer cells }\end{array}$ & AXL & $\begin{array}{l}\text { Inhibition of GAS6-mediated AXL } \\
\text { downregulation }{ }^{[65,66]}\end{array}$ \\
\hline $\begin{array}{c}\text { MCF7, ZR-75, MDA-MB- } \\
231 \text { and MDA-MB-468 } \\
\text { breast cancer cells }\end{array}$ & RON & Transcriptional activation by HIF- $1 \alpha^{[69]}$ \\
\hline Numerous cancer types & VEGF-A & Transcriptional activation by HIF- $1 \alpha^{[13,18,23]}$ \\
\hline $\begin{array}{l}\text { Rat pulmonary } \\
\text { microvascular smooth } \\
\text { muscle cells }\end{array}$ & VEGF-D & Transcriptional activation by HIF- $1 \alpha^{[28]}$ \\
\hline $\begin{array}{l}\text { Bovine retinal endothelial } \\
\text { cells, bovine retinal pericytes }\end{array}$ & VEGF & $\begin{array}{l}\text { Enhanced mRNA due to increased protein kinase } \\
\text { A (PKA) activity }{ }^{[29,30]}\end{array}$ \\
\hline $\begin{array}{l}\text { U87 glioblastoma cells, } 293 \\
\text { human embryonic kidney } \\
\text { cells }\end{array}$ & VEGF & Expression induced by increased SRC activity ${ }^{[31]}$ \\
\hline $\begin{array}{l}\text { Rat pheochromocytoma } \\
\text { cells, rat heart myocytes, rat } \\
\text { glioma cells }\end{array}$ & VEGF & mRNA stabilization $^{[32-34]}$ \\
\hline $\begin{array}{l}\text { MDA-MB-231 and MDA- } \\
\text { MB- } 435 \text { breast cancer cells, } \\
\text { U87, U251 and A172 } \\
\text { glioblastoma cells }\end{array}$ & PDGF-B & Transcriptional activation by HIF- $1 \alpha^{[36,37]}$ \\
\hline HEPG2 HCC cells, mouse & IGF2 & Increased expression indirectly mediated by HIF- \\
\hline
\end{tabular}




\begin{tabular}{|c|c|c|}
\hline $\begin{array}{l}\text { embryonic fibroblast and } \\
\text { embryonic stem cells }\end{array}$ & & $1 \alpha^{[41-43]}$ \\
\hline 786-0 ccRCC cells & $\mathrm{TGF} \alpha$ & $\begin{array}{l}\text { Production induced by increased HIF in VHL null } \\
\text { cells }{ }^{[45]}\end{array}$ \\
\hline $\begin{array}{l}\text { Astrocytes isolated from } \\
\text { stroke-prone spontaneously } \\
\text { hypertensive rats }\end{array}$ & GDNF & $\begin{array}{l}\text { Increased expression potentially mediated by } \\
\text { HIF- } 1 \alpha^{[130,168]}\end{array}$ \\
\hline $\begin{array}{l}\text { Non-small cell lung cancer } \\
\text { (NSCLC), RCC, breast } \\
\text { cancer, prostate cancer, } \\
\text { glioblastoma cells }\end{array}$ & EGFR & m9] $_{\text {mANA translation through activated HIF- } 2 \alpha^{[76,}}$ \\
\hline 786-0 ccRCC cells & EGFR & Delayed receptor endocytosis ${ }^{[81]}$ \\
\hline 786-O ccRCC & EGFR & $\begin{array}{l}\text { Ligand-independent activation through elevated } \\
\text { expression of CAV1 }{ }^{[86]}\end{array}$ \\
\hline $\begin{array}{l}\text { T-47D and MDA-MB-468 } \\
\text { breast cancer cells, HEK } 293 \\
\text { human embryonic kidney } \\
\text { cells }\end{array}$ & HER4 & Delayed receptor endocytosis ${ }^{[82]}$ \\
\hline $\begin{array}{l}\text { Caco- } 2 \text { colorectal } \\
\text { adenocarcinoma cells }\end{array}$ & HER2/HER3 & $\begin{array}{l}\text { Enhanced signalling through downregulation of } \\
\text { Necl-2 }\end{array}$ \\
\hline $\begin{array}{l}\text { PC9 and HCC827 NSCLC } \\
\text { cells }\end{array}$ & IGF1R & $\begin{array}{l}\text { Enhanced signalling in Gefitinib-resistant CSC } \\
\text { [92] }\end{array}$ \\
\hline $\begin{array}{l}\text { RT4, RT112 and T24 } \\
\text { bladder cancer cell lines }\end{array}$ & FGFR3 & $\begin{array}{l}\text { Increased mRNA levels through suppression of } \\
\text { miR-100 }\end{array}$ \\
\hline
\end{tabular}

\section{Figure legends}

Figure 1: Hypoxia-induced activation of RTK systems (See text for details)

Figure 2: Signaling by RTK activates the HIF pathway (See text for details)

\section{Acknowledgments}

This work has been supported by grants from the Werner und Hedy Berger-Janser Stiftung (to $\mathrm{MM}$ ) and Stiftung für klinisch-experimentelle Tumorforschung (to $\mathrm{YZ}$ and MM). 


\section{References}

1. Pierce, A.M. and A.K. Keating, TAM receptor tyrosine kinases: expression, disease and oncogenesis in the central nervous system. Brain Res, 2014. 1542: p. 206-20.

2. Lemmon, M.A. and J. Schlessinger, Cell signaling by receptor tyrosine kinases. Cell, 2010. 141(7): p. 1117-34.

3. Ullrich, A. and J. Schlessinger, Signal transduction by receptors with tyrosine kinase activity. Cell, 1990. 61(2): p. 203-12.

4. Choura, M. and A. Rebai, Receptor tyrosine kinases: from biology to pathology. J Recept Signal Transduct Res, 2011. 31(6): p. 387-94.

5. Casaletto, J.B. and A.I. McClatchey, Spatial regulation of receptor tyrosine kinases in development and cancer. Nat Rev Cancer, 2012. 12(6): p. 387-400.

6. Paul, M.K. and A.K. Mukhopadhyay, Tyrosine kinase - Role and significance in Cancer. Int J Med Sci, 2004. 1(2): p. 101-115.

7. Niederst, M.J. and J.A. Engelman, Bypass mechanisms of resistance to receptor tyrosine kinase inhibition in lung cancer. Sci Signal, 2013. 6(294): p. re6.

8. Hanahan, D. and R.A. Weinberg, Hallmarks of cancer: the next generation. Cell, 2011. 144(5): p. 646-74.

9. Takeuchi, K. and F. Ito, Receptor tyrosine kinases and targeted cancer therapeutics. Biol Pharm Bull, 2011. 34(12): p. 1774-80.

10. Gherardi, E., et al., Targeting MET in cancer: rationale and progress. Nat Rev Cancer, 2012. 12(2): p. 89-103.

11. Rosenzweig, S.A., Acquired resistance to drugs targeting receptor tyrosine kinases. Biochem Pharmacol, 2012. 83(8): p. 1041-8.

12. Yi-fan, C. and F. Li-wu, Mechanisms of acquired resistance to tyrosine kinase inhibitors. Acta Pharmaceutica Sinica B, 2011. 1(4): p. 197-207.

13. Harris, A.L., Hypoxia--a key regulatory factor in tumour growth. Nat Rev Cancer, 2002. 2(1): p. 38-47.

14. Multhoff, G., J. Radons, and P. Vaupel, Critical role of aberrant angiogenesis in the development of tumor hypoxia and associated radioresistance. Cancers (Basel), 2014. 6(2): p. 813-28.

15. Michieli, P., Hypoxia, angiogenesis and cancer therapy: to breathe or not to breathe? Cell Cycle, 2009. 8(20): p. 3291-6.

16. Ruan, K., G. Song, and G. Ouyang, Role of hypoxia in the hallmarks of human cancer. J Cell Biochem, 2009. 107(6): p. 1053-62.

17. Boccaccio, C. and P.M. Comoglio, Invasive growth: a MET-driven genetic programme for cancer and stem cells. Nat Rev Cancer, 2006. 6(8): p. 637-45.

18. Forsythe, J.A., et al., Activation of vascular endothelial growth factor gene transcription by hypoxia-inducible factor 1. Mol Cell Biol, 1996. 16(9): p. 4604-13.

19. Denko, N., et al., Epigenetic regulation of gene expression in cervical cancer cells by the tumor microenvironment. Clin Cancer Res, 2000. 6(2): p. 480-7.

20. Koong, A.C., et al., Candidate genes for the hypoxic tumor phenotype. Cancer Res, 2000. 60(4): p. 883-7.

21. Wykoff, C.C., et al., Identification of novel hypoxia dependent and independent target genes of the von Hippel-Lindau (VHL) tumour suppressor by mRNA differential expression profiling. Oncogene, 2000. 19(54): p. 6297-305.

22. Lal, A., et al., Transcriptional response to hypoxia in human tumors. J Natl Cancer Inst, 2001. 93(17): p. 1337-43.

23. Simiantonaki, N., et al., Hypoxia-induced epithelial VEGF-C/VEGFR-3 upregulation in carcinoma cell lines. Int J Oncol, 2008. 32(3): p. 585-92.

24. Ferrara, N. and T. Davis-Smyth, The biology of vascular endothelial growth factor. Endocr Rev, 1997. 18(1): p. 4-25. 
25. Abdel-Rahman, O., Targeting vascular endothelial growth factor (VEGF) pathway in gastric cancer: Preclinical and clinical aspects. Crit Rev Oncol Hematol, 2014.

26. Hamerlik, P., et al., Autocrine VEGF-VEGFR2-Neuropilin-1 signaling promotes glioma stem-like cell viability and tumor growth. J Exp Med, 2012. 209(3): p. 507-20.

27. Mercurio, A.M., et al., Autocrine signaling in carcinoma: VEGF and the alpha6beta4 integrin. Semin Cancer Biol, 2004. 14(2): p. 115-22.

28. Teng, X., D. Li, and R.A. Johns, Hypoxia up-regulates mouse vascular endothelial growth factor D promoter activity in rat pulmonary microvascular smooth-muscle cells. Chest, 2002. 121(3 Suppl): p. 82S-83S.

29. Bontemps, F., M.F. Vincent, and G. Van den Berghe, Mechanisms of elevation of adenosine levels in anoxic hepatocytes. Biochem J, 1993. 290 ( Pt 3): p. 671-7.

30. Takagi, H., et al., Adenosine mediates hypoxic induction of vascular endothelial growth factor in retinal pericytes and endothelial cells. Invest Ophthalmol Vis Sci, 1996. 37(11): p. 2165-76.

31. Mukhopadhyay, D., et al., Hypoxic induction of human vascular endothelial growth factor expression through c-Src activation. Nature, 1995. 375(6532): p. 577-81.

32. Levy, A.P., N.S. Levy, and M.A. Goldberg, Post-transcriptional regulation of vascular endothelial growth factor by hypoxia. J Biol Chem, 1996. 271(5): p. 2746-53.

33. Ikeda, E., et al., Hypoxia-induced transcriptional activation and increased mRNA stability of vascular endothelial growth factor in C6 glioma cells. J Biol Chem, 1995. 270(34): p. 19761-6.

34. Stein, I., et al., Stabilization of vascular endothelial growth factor mRNA by hypoxia and hypoglycemia and coregulation with other ischemia-induced genes. Mol Cell Biol, 1995. 15(10): p. 5363-8.

35. Chung, A.S., J. Lee, and N. Ferrara, Targeting the tumour vasculature: insights from physiological angiogenesis. Nat Rev Cancer, 2010. 10(7): p. 505-14.

36. Schito, L., et al., Hypoxia-inducible factor 1-dependent expression of platelet-derived growth factor B promotes lymphatic metastasis of hypoxic breast cancer cells. Proc Natl Acad Sci U S A, 2012. 109(40): p. E2707-16.

37. Yoshida, D., et al., Hypoxia inducible factor 1-alpha regulates of platelet derived growth factor-B in human glioblastoma cells. J Neurooncol, 2006. 76(1): p. 13-21.

38. Boursi, B., et al., Digoxin use and the risk for colorectal cancer. Pharmacoepidemiol Drug Saf, 2014. 23(11): p. 1147-53.

39. Enguita-Germán, M. and P. Fortes, Targeting the insulin-like growth factor pathway in hepatocellular carcinoma. World J Hepatol, 2014. 6(10): p. 716-37.

40. Fukuda, R., et al., Insulin-like growth factor 1 induces hypoxia-inducible factor 1-mediated vascular endothelial growth factor expression, which is dependent on MAP kinase and phosphatidylinositol 3-kinase signaling in colon cancer cells. J Biol Chem, 2002. 277(41): p. 38205-11.

41. Zhang, L., et al., Gene expression profiles in normal and cancer cells. Science, 1997. 276(5316): p. 1268-72.

42. Kim, K.W., et al., Insulin-like growth factor II induced by hypoxia may contribute to angiogenesis of human hepatocellular carcinoma. Cancer Res, 1998. 58(2): p. 348-51.

43. Feldser, D., et al., Reciprocal positive regulation of hypoxia-inducible factor 1alpha and insulin-like growth factor 2. Cancer Res, 1999. 59(16): p. 3915-8.

44. Linehan, W.M., M.I. Lerman, and B. Zbar, Identification of the von Hippel-Lindau (VHL) gene. Its role in renal cancer. JAMA, 1995. 273(7): p. 564-70.

45. Gunaratnam, L., et al., Hypoxia inducible factor activates the transforming growth factoralpha/epidermal growth factor receptor growth stimulatory pathway in VHL(-/-) renal cell carcinoma cells. J Biol Chem, 2003. 278(45): p. 44966-74.

46. Ciardiello, F., et al., Cooperative inhibition of renal cancer growth by anti-epidermal growth factor receptor antibody and protein kinase A antisense oligonucleotide. J Natl Cancer Inst, 1998. 90(14): p. 1087-94. 
47. Prewett, M., et al., Mouse-human chimeric anti-epidermal growth factor receptor antibody C225 inhibits the growth of human renal cell carcinoma xenografts in nude mice. Clin Cancer Res, 1998. 4(12): p. 2957-66.

48. Iliopoulos, O., et al., Tumour suppression by the human von Hippel-Lindau gene product. Nat Med, 1995. 1(8): p. 822-6.

49. Pennacchietti, S., et al., Hypoxia promotes invasive growth by transcriptional activation of the met protooncogene. Cancer Cell, 2003. 3(4): p. 347-61.

50. Semenza, G.L., HIF-1, O(2), and the 3 PHDs: how animal cells signal hypoxia to the nucleus. Cell, 2001. 107(1): p. 1-3.

51. Canning, M.T., et al., Oxygen-mediated regulation of gelatinase and tissue inhibitor of metalloproteinases-1 expression by invasive cells. Exp Cell Res, 2001. 267(1): p. 88-94.

52. Miyazaki, Y., et al., The effect of hypoxic microenvironment on matrix metalloproteinase expression in xenografts of human oral squamous cell carcinoma. Int J Oncol, 2008. 32(1): p. 145-51.

53. Graham, C.H., T.E. Fitzpatrick, and K.R. McCrae, Hypoxia stimulates urokinase receptor expression through a heme protein-dependent pathway. Blood, 1998. 91(9): p. 3300-7.

54. Naldini, L., et al., Extracellular proteolytic cleavage by urokinase is required for activation of hepatocyte growth factor/scatter factor. EMBO J, 1992. 11(13): p. 4825-33.

55. Ide, T., et al., Tumor-stromal cell interaction under hypoxia increases the invasiveness of pancreatic cancer cells through the hepatocyte growth factor/c-Met pathway. Int J Cancer, 2006. 119(12): p. 2750-9.

56. Buchanan, I.M., et al., Radiosensitization of glioma cells by modulation of Met signalling with the hepatocyte growth factor neutralizing antibody, AMG102. J Cell Mol Med, 2011. 15(9): p. 1999-2006.

57. Welsh, J.W., et al., The c-Met receptor tyrosine kinase inhibitor MP470 radiosensitizes glioblastoma cells. Radiat Oncol, 2009. 4: p. 69.

58. Medova, M., D.M. Aebersold, and Y. Zimmer, MET inhibition in tumor cells by PHA665752 impairs homologous recombination repair of DNA double strand breaks. Int J Cancer, 2012. 130(3): p. 728-34.

59. Lee, Y.H., B.L. Morrison, and D.P. Bottaro, Synergistic signaling of tumor cell invasiveness by hepatocyte growth factor and hypoxia. J Biol Chem, 2014. 289(30): p. 20448-61.

60. Abedin, M.J., et al., Autophagy delays apoptotic death in breast cancer cells following DNA damage. Cell Death Differ, 2007. 14(3): p. 500-10.

61. Pursiheimo, J.P., et al., Hypoxia-activated autophagy accelerates degradation of SQSTM1/p62. Oncogene, 2009. 28(3): p. 334-44.

62. Rankin, E.B., et al., Direct regulation of GAS6/AXL signaling by HIF promotes renal metastasis through SRC and MET. Proc Natl Acad Sci U S A, 2014. 111(37): p. 13373-8.

63. Dulak, A.M., et al., HGF-independent potentiation of EGFR action by c-Met. Oncogene, 2011. 30(33): p. 3625-35.

64. Linger, R.M., et al., TAM receptor tyrosine kinases: biologic functions, signaling, and potential therapeutic targeting in human cancer. Adv Cancer Res, 2008. 100: p. 35-83.

65. Valverde, P., Effects of Gas6 and hydrogen peroxide in Axl ubiquitination and downregulation. Biochem Biophys Res Commun, 2005. 333(1): p. 180-5.

66. Mishra, A., et al., Hypoxia stabilizes GAS6/Axl signaling in metastatic prostate cancer. Mol Cancer Res, 2012. 10(6): p. 703-12.

67. Follenzi, A., et al., Cross-talk between the proto-oncogenes Met and Ron. Oncogene, 2000. 19(27): p. 3041-9.

68. Leonis, M.A., M.N. Thobe, and S.E. Waltz, Ron-receptor tyrosine kinase in tumorigenesis and metastasis. Future Oncol, 2007. 3(4): p. 441-8.

69. Thangasamy, A., J. Rogge, and S. Ammanamanchi, Recepteur d'origine nantais tyrosine kinase is a direct target of hypoxia-inducible factor-1alpha-mediated invasion of breast carcinoma cells. J Biol Chem, 2009. 284(21): p. 14001-10. 
70. Chang, H.Y., et al., Hypoxia promotes nuclear translocation and transcriptional function in the oncogenic tyrosine kinase RON. Cancer Res, 2014. 74(16): p. 4549-62.

71. Arteaga, C.L. and J.A. Engelman, ERBB receptors: from oncogene discovery to basic science to mechanism-based cancer therapeutics. Cancer Cell, 2014. 25(3): p. 282-303.

72. Momose, K., et al., miR-214 and hypoxia down-regulate Necl-2/CADM1 and enhance ErbB2/ErbB3 signaling. Genes Cells, 2013. 18(3): p. 195-202.

73. Schraml, P., et al., Tissue microarrays for gene amplification surveys in many different tumor types. Clin Cancer Res, 1999. 5(8): p. 1966-75.

74. Yarden, Y. and M.X. Sliwkowski, Untangling the ErbB signalling network. Nat Rev Mol Cell Biol, 2001. 2(2): p. 127-37.

75. Lahiry, P., et al., Kinase mutations in human disease: interpreting genotype-phenotype relationships. Nat Rev Genet, 2010. 11(1): p. 60-74.

76. Swinson, D.E. and K.J. O'Byrne, Interactions between hypoxia and epidermal growth factor receptor in non-small-cell lung cancer. Clin Lung Cancer, 2006. 7(4): p. 250-6.

77. Sun, H., et al., Niacin Activates the PI3K/Akt Cascade via PKC- and EGFR-TransactivationDependent Pathways through Hydroxyl-Carboxylic Acid Receptor 2. PLoS One, 2014. 9(11): p. e112310.

78. Leon Carrion, S., C.H. Sutter, and T.R. Sutter, Combined treatment with sodium butyrate and PD153035 enhances keratinocyte differentiation. Exp Dermatol, 2014. 23(3): p. 211-4.

79. Franovic, A., et al., Translational up-regulation of the EGFR by tumor hypoxia provides a nonmutational explanation for its overexpression in human cancer. Proc Natl Acad Sci U S A, 2007. 104(32): p. 13092-7.

80. Wang, X. and A. Schneider, HIF-2alpha-mediated activation of the epidermal growth factor receptor potentiates head and neck cancer cell migration in response to hypoxia. Carcinogenesis, 2010. 31(7): p. 1202-10.

81. Wang, Y., et al., Regulation of endocytosis via the oxygen-sensing pathway. Nat Med, 2009. 15(3): p. 319-24.

82. Paatero, I., et al., Hypoxia-inducible factor-1 $\alpha$ induces ErbB4 signaling in the differentiating mammary gland. J Biol Chem, 2014. 289(32): p. 22459-69.

83. Paatero, I., et al., Hypoxia-inducible factor-1alpha induces ErbB4 signaling in the differentiating mammary gland. J Biol Chem, 2014. 289(32): p. 22459-69.

84. Pfeffer, S.R., Motivating endosome motility. Nat Cell Biol, 1999. 1(6): p. E145-7.

85. Bucci, C., et al., The small GTPase rab5 functions as a regulatory factor in the early endocytic pathway. Cell, 1992. 70(5): p. 715-28.

86. Wang, Y., et al., Hypoxia promotes ligand-independent EGF receptor signaling via hypoxiainducible factor-mediated upregulation of caveolin-1. Proc Natl Acad Sci U S A, 2012. 109(13): p. 4892-7.

87. Parton, R.G. and K. Simons, The multiple faces of caveolae. Nat Rev Mol Cell Biol, 2007. 8(3): p. $185-94$.

88. Kawano, S., et al., Silencing of ErbB3/ErbB2 signaling by immunoglobulin-like Necl-2. J Biol Chem, 2009. 284(35): p. 23793-805.

89. Murakami, Y., Involvement of a cell adhesion molecule, TSLC1/IGSF4, in human oncogenesis. Cancer Sci, 2005. 96(9): p. 543-52.

90. Semenza, G.L., Hypoxia-inducible factor 1: master regulator of 02 homeostasis. Curr Opin Genet Dev, 1998. 8(5): p. 588-94.

91. Carmeliet, P., et al., Role of HIF-1alpha in hypoxia-mediated apoptosis, cell proliferation and tumour angiogenesis. Nature, 1998. 394(6692): p. 485-90.

92. Murakami, A., et al., Hypoxia increases gefitinib-resistant lung cancer stem cells through the activation of insulin-like growth factor 1 receptor. PLoS One, 2014. 9(1): p. e86459.

93. Trumpp, A. and O.D. Wiestler, Mechanisms of Disease: cancer stem cells--targeting the evil twin. Nat Clin Pract Oncol, 2008. 5(6): p. 337-47.

94. Li, L. and R. Bhatia, Stem cell quiescence. Clin Cancer Res, 2011. 17(15): p. 4936-41. 
95. Lin, Q. and Z. Yun, Impact of the hypoxic tumor microenvironment on the regulation of cancer stem cell characteristics. Cancer Biol Ther, 2010. 9(12): p. 949-56.

96. Dallas, N.A., et al., Chemoresistant colorectal cancer cells, the cancer stem cell phenotype, and increased sensitivity to insulin-like growth factor-I receptor inhibition. Cancer Res, 2009. 69(5): p. 1951-7.

97. Komsuoglu Celikyurt, I., et al., Effects of YC-1 on learning and memory functions of aged rats. Med Sci Monit Basic Res, 2014. 20: p. 130-7.

98. Blick, C., et al., Hypoxia regulates FGFR3 expression via HIF-1 $\alpha$ and miR-100 and contributes to cell survival in non-muscle invasive bladder cancer. Br J Cancer, 2013. 109(1): p. 50-9.

99. Pillai, R.S., S.N. Bhattacharyya, and W. Filipowicz, Repression of protein synthesis by miRNAs: how many mechanisms? Trends Cell Biol, 2007. 17(3): p. 118-26.

100. Meltzer, P.S., Cancer genomics: small RNAs with big impacts. Nature, 2005. 435(7043): p. 745-6.

101. Catto, J.W., et al., Distinct microRNA alterations characterize high-and low-grade bladder cancer. Cancer Res, 2009. 69(21): p. 8472-81.

102. Degnin, C.R., M.B. Laederich, and W.A. Horton, Ligand activation leads to regulated intramembrane proteolysis of fibroblast growth factor receptor 3. Mol Biol Cell, 2011. 22(20): p. 3861-73.

103. Buffa, F.M., et al., microRNA-associated progression pathways and potential therapeutic targets identified by integrated mRNA and microRNA expression profiling in breast cancer. Cancer Res, 2011. 71(17): p. 5635-45.

104. Zhong, H., et al., Modulation of hypoxia-inducible factor 1alpha expression by the epidermal growth factor/phosphatidylinositol 3-kinase/PTEN/AKT/FRAP pathway in human prostate cancer cells: implications for tumor angiogenesis and therapeutics. Cancer Res, 2000. 60(6): p. 1541-5.

105. Phillips, R.J., et al., Epidermal growth factor and hypoxia-induced expression of CXC chemokine receptor 4 on non-small cell lung cancer cells is regulated by the phosphatidylinositol 3-kinase/PTEN/AKT/mammalian target of rapamycin signaling pathway and activation of hypoxia inducible factor-1alpha. J Biol Chem, 2005. 280(23): p. 22473-81.

106. Peng, X.H., et al., Cross-talk between epidermal growth factor receptor and hypoxia-inducible factor-1alpha signal pathways increases resistance to apoptosis by up-regulating survivin gene expression. J Biol Chem, 2006. 281(36): p. 25903-14.

107. Secades, P., et al., Increase in gene dosage is a mechanism of HIF-1alpha constitutive expression in head and neck squamous cell carcinomas. Genes Chromosomes Cancer, 2009. 48(5): p. 441-54.

108. Vaupel, P., Tumor microenvironmental physiology and its implications for radiation oncology. Semin Radiat Oncol, 2004. 14(3): p. 198-206.

109. Li, Y.M., et al., A hypoxia-independent hypoxia-inducible factor-1 activation pathway induced by phosphatidylinositol-3 kinase/Akt in HER2 overexpressing cells. Cancer Res, 2005. 65(8): p. 3257-63.

110. Laughner, E., et al., HER2 (neu) signaling increases the rate of hypoxia-inducible factor 1alpha (HIF-1alpha) synthesis: novel mechanism for HIF-1-mediated vascular endothelial growth factor expression. Mol Cell Biol, 2001. 21(12): p. 3995-4004.

111. Cheng, J.C., C. Klausen, and P.C. Leung, Hypoxia-inducible factor 1 alpha mediates epidermal growth factor-induced down-regulation of E-cadherin expression and cell invasion in human ovarian cancer cells. Cancer Lett, 2013. 329(2): p. 197-206.

112. Pore, N., et al., EGFR tyrosine kinase inhibitors decrease VEGF expression by both hypoxiainducible factor (HIF)-1-independent and HIF-1-dependent mechanisms. Cancer Res, 2006. 66(6): p. 3197-204.

113. Vivanco, I. and C.L. Sawyers, The phosphatidylinositol 3-Kinase AKT pathway in human cancer. Nat Rev Cancer, 2002. 2(7): p. 489-501. 
114. Lewis, T.S., P.S. Shapiro, and N.G. Ahn, Signal transduction through MAP kinase cascades. Adv Cancer Res, 1998. 74: p. 49-139.

115. Serra-Pérez, A., et al., Extended ischemia prevents HIF1alpha degradation at reoxygenation by impairing prolyl-hydroxylation: role of Krebs cycle metabolites. J Biol Chem, 2010. 285(24): p. 18217-24.

116. Secades, P., et al., In vitro study of normoxic epidermal growth factor receptor-induced hypoxia-inducible factor-1-alpha, vascular endothelial growth factor, and BNIP3 expression in head and neck squamous cell carcinoma cell lines: Implications for anti-epidermal growth factor receptor therapy. Head Neck, 2014.

117. Jiang, B.H., et al., Phosphatidylinositol 3-kinase signaling controls levels of hypoxia-inducible factor 1. Cell Growth Differ, 2001. 12(7): p. 363-9.

118. Pegram, M.D., G. Pauletti, and D.J. Slamon, HER-2/neu as a predictive marker of response to breast cancer therapy. Breast Cancer Res Treat, 1998. 52(1-3): p. 65-77.

119. Rilke, F., et al., Prognostic significance of HER-2/neu expression in breast cancer and its relationship to other prognostic factors. Int J Cancer, 1991. 49(1): p. 44-9.

120. Tzahar, E. and Y. Yarden, The ErbB-2/HER2 oncogenic receptor of adenocarcinomas: from orphanhood to multiple stromal ligands. Biochim Biophys Acta, 1998. 1377(1): p. M25-37.

121. Bagheri-Yarmand, R., et al., Vascular endothelial growth factor up-regulation via p21activated kinase-1 signaling regulates heregulin-beta1-mediated angiogenesis. J Biol Chem, 2000. 275(50): p. 39451-7.

122. Yen, L., et al., Heregulin selectively upregulates vascular endothelial growth factor secretion in cancer cells and stimulates angiogenesis. Oncogene, 2000. 19(31): p. 3460-9.

123. Petit, A.M., et al., Neutralizing antibodies against epidermal growth factor and ErbB-2/neu receptor tyrosine kinases down-regulate vascular endothelial growth factor production by tumor cells in vitro and in vivo: angiogenic implications for signal transduction therapy of solid tumors. Am J Pathol, 1997. 151(6): p. 1523-30.

124. Jiang, B.H., et al., Transactivation and inhibitory domains of hypoxia-inducible factor 1alpha. Modulation of transcriptional activity by oxygen tension. J Biol Chem, 1997. 272(31): p. 19253-60.

125. Kazi, A.A., et al., Nonhypoxic regulation and role of hypoxia-inducible factor 1 in aromatase inhibitor resistant breast cancer. Breast Cancer Res, 2014. 16(1): p. R15.

126. Chumsri, S., et al., Aromatase, aromatase inhibitors, and breast cancer. J Steroid Biochem Mol Biol, 2011. 125(1-2): p. 13-22.

127. Sabnis, G. and A. Brodie, Adaptive changes results in activation of alternate signaling pathways and resistance to aromatase inhibitor resistance. Mol Cell Endocrinol, 2011. 340(2): p. 142-7.

128. Paatero, I., et al., Interaction with ErbB4 promotes hypoxia-inducible factor-1alpha signaling. J Biol Chem, 2012. 287(13): p. 9659-71.

129. Liu, Y.V., et al., RACK1 competes with HSP9O for binding to HIF-1alpha and is required for O(2)-independent and HSP9O inhibitor-induced degradation of HIF-1alpha. Mol Cell, 2007. 25(2): p. 207-17.

130. Nilsson, M.B., et al., Multiple receptor tyrosine kinases regulate HIF-1alpha and HIF-2alpha in normoxia and hypoxia in neuroblastoma: implications for antiangiogenic mechanisms of multikinase inhibitors. Oncogene, 2010. 29(20): p. 2938-49.

131. Holmquist-Mengelbier, L., et al., Recruitment of HIF-1alpha and HIF-2alpha to common target genes is differentially regulated in neuroblastoma: HIF-2alpha promotes an aggressive phenotype. Cancer Cell, 2006. 10(5): p. 413-23.

132. Das, B., et al., A hypoxia-driven vascular endothelial growth factor/Flt1 autocrine loop interacts with hypoxia-inducible factor-1alpha through mitogen-activated protein kinase/extracellular signal-regulated kinase 1/2 pathway in neuroblastoma. Cancer Res, 2005. 65(16): p. 7267-75. 
133. Tang, N., et al., Loss of HIF-1alpha in endothelial cells disrupts a hypoxia-driven VEGF autocrine loop necessary for tumorigenesis. Cancer Cell, 2004. 6(5): p. 485-95.

134. Ferrara, N., Role of vascular endothelial growth factor in physiologic and pathologic angiogenesis: therapeutic implications. Semin Oncol, 2002. 29(6 Suppl 16): p. 10-4.

135. Santos, S.C. and S. Dias, Internal and external autocrine VEGF/KDR loops regulate survival of subsets of acute leukemia through distinct signaling pathways. Blood, 2004. 103(10): p. 38839.

136. Wang, E.S., et al., Targeting autocrine and paracrine VEGF receptor pathways inhibits human lymphoma xenografts in vivo. Blood, 2004. 104(9): p. 2893-902.

137. Steiner, H.H., et al., Autocrine pathways of the vascular endothelial growth factor (VEGF) in glioblastoma multiforme: clinical relevance of radiation-induced increase of VEGF levels. J Neurooncol, 2004. 66(1-2): p. 129-38.

138. Xu, L., et al., Epidermal growth factor receptor regulates MET levels and invasiveness through hypoxia-inducible factor-1alpha in non-small cell lung cancer cells. Oncogene, 2010. 29(18): p. 2616-27.

139. Tacchini, L., et al., Hepatocyte growth factor signalling stimulates hypoxia inducible factor-1 (HIF-1) activity in HepG2 hepatoma cells. Carcinogenesis, 2001. 22(9): p. 1363-71.

140. Tacchini, L., et al., Hepatocyte growth factor-activated NF-kappaB regulates HIF-1 activity and ODC expression, implicated in survival, differently in different carcinoma cell lines. Carcinogenesis, 2004. 25(11): p. 2089-100.

141. Neill, T., et al., Decorin antagonizes the angiogenic network: concurrent inhibition of Met, hypoxia inducible factor 1alpha, vascular endothelial growth factor $A$, and induction of thrombospondin-1 and TIMP3. J Biol Chem, 2012. 287(8): p. 5492-506.

142. Iozzo, R.V., et al., Decorin is a biological ligand for the epidermal growth factor receptor. J Biol Chem, 1999. 274(8): p. 4489-92.

143. Moscatello, D.K., et al., Decorin suppresses tumor cell growth by activating the epidermal growth factor receptor. J Clin Invest, 1998. 101(2): p. 406-12.

144. Csordas, G., et al., Sustained down-regulation of the epidermal growth factor receptor by decorin. A mechanism for controlling tumor growth in vivo. J Biol Chem, 2000. 275(42): p. 32879-87.

145. Santra, M., I. Eichstetter, and R.V. Iozzo, An anti-oncogenic role for decorin. Down-regulation of ErbB2 leads to growth suppression and cytodifferentiation of mammary carcinoma cells. J Biol Chem, 2000. 275(45): p. 35153-61.

146. Buraschi, S., et al., Decorin antagonizes Met receptor activity and down-regulates $\{$ beta\}catenin and Myc levels. J Biol Chem, 2010. 285(53): p. 42075-85.

147. Gariboldi, M.B., R. Ravizza, and E. Monti, The IGFR1 inhibitor NVP-AEW541 disrupts a prosurvival and pro-angiogenic IGF-STAT3-HIF1 pathway in human glioblastoma cells. Biochem Pharmacol, 2010. 80(4): p. 455-62.

148. Chitnis, M.M., et al., The type 1 insulin-like growth factor receptor pathway. Clin Cancer Res, 2008. 14(20): p. 6364-70.

149. Harrington, L.S., G.M. Findlay, and R.F. Lamb, Restraining PI3K: mTOR signalling goes back to the membrane. Trends Biochem Sci, 2005. 30(1): p. 35-42.

150. Brantley, E.C., et al., Loss of protein inhibitors of activated STAT-3 expression in glioblastoma multiforme tumors: implications for STAT-3 activation and gene expression. Clin Cancer Res, 2008. 14(15): p. 4694-704.

151. Xu, Q., et al., Targeting Stat3 blocks both HIF-1 and VEGF expression induced by multiple oncogenic growth signaling pathways. Oncogene, 2005. 24(36): p. 5552-60.

152. Blakesley, V.A., et al., Signaling via the insulin-like growth factor-I receptor: does it differ from insulin receptor signaling? Cytokine Growth Factor Rev, 1996. 7(2): p. 153-9.

153. Zelzer, E., et al., Insulin induces transcription of target genes through the hypoxia-inducible factor HIF-1alpha/ARNT. EMBO J, 1998. 17(17): p. 5085-94. 
154. Bunn, H.F. and R.O. Poyton, Oxygen sensing and molecular adaptation to hypoxia. Physiol Rev, 1996. 76(3): p. 839-85.

155. Pilkis, S.J. and D.K. Granner, Molecular physiology of the regulation of hepatic gluconeogenesis and glycolysis. Annu Rev Physiol, 1992. 54: p. 885-909.

156. Treins, C., et al., Insulin stimulates hypoxia-inducible factor 1 through a phosphatidylinositol 3-kinase/target of rapamycin-dependent signaling pathway. J Biol Chem, 2002. 277(31): p. 27975-81.

157. Funatsu, H., et al., Stimulation and inhibition of angiogenesis in diabetic retinopathy. Jpn J Ophthalmol, 2001. 45(6): p. 577-84.

158. Wang, D., et al., Induction of vascular endothelial growth factor expression in endothelial cells by platelet-derived growth factor through the activation of phosphatidylinositol 3-kinase. Cancer Res, 1999. 59(7): p. 1464-72.

159. Richard, D.E., E. Berra, and J. Pouyssegur, Nonhypoxic pathway mediates the induction of hypoxia-inducible factor 1alpha in vascular smooth muscle cells. J Biol Chem, 2000. 275(35): p. 26765-71.

160. Ader, I., et al., Preclinical evidence that SSR128129E--a novel small-molecule multi-fibroblast growth factor receptor blocker--radiosensitises human glioblastoma. Eur J Cancer, 2014. 50(13): p. 2351-9.

161. Calvani, M., et al., Hypoxic induction of an HIF-1alpha-dependent bFGF autocrine loop drives angiogenesis in human endothelial cells. Blood, 2006. 107(7): p. 2705-12.

162. Ader, I., et al., In vitro and in vivo radiosensitization by FGFR-1 inhibition using the antagonist SSR128129E in human glioblastoma models. Neuro-Oncology, 2010. 12(suppl 4).

163. Skuli, N., et al., Activation of RhoB by hypoxia controls hypoxia-inducible factor-1alpha stabilization through glycogen synthase kinase-3 in U87 glioblastoma cells. Cancer Res, 2006. 66(1): p. 482-9.

164. Wykoff, C.C., et al., Hypoxia-inducible expression of tumor-associated carbonic anhydrases. Cancer Res, 2000. 60(24): p. 7075-83.

165. Ditte, P., et al., Phosphorylation of carbonic anhydrase IX controls its ability to mediate extracellular acidification in hypoxic tumors. Cancer Res, 2011. 71(24): p. 7558-67.

166. Pastorek, J., et al., Cloning and characterization of $M N$, a human tumor-associated protein with a domain homologous to carbonic anhydrase and a putative helix-loop-helix DNA binding segment. Oncogene, 1994. 9(10): p. 2877-88.

167. Takacova, M., et al., Expression pattern of carbonic anhydrase IX in Medullary thyroid carcinoma supports a role for RET-mediated activation of the HIF pathway. Am J Pathol, 2014. 184(4): p. 953-65.

168. Yamagata, K., et al., Differential regulation of glial cell line-derived neurotrophic factor (GDNF) mRNA expression during hypoxia and reoxygenation in astrocytes isolated from stroke-prone spontaneously hypertensive rats. Glia, 2002. 37(1): p. 1-7.

169. Semenza, G.L., Hypoxia-inducible factors: mediators of cancer progression and targets for cancer therapy. Trends Pharmacol Sci, 2012. 33(4): p. 207-14.

170. Mijatovic, T., et al., Cardiotonic steroids on the road to anti-cancer therapy. Biochim Biophys Acta, 2007. 1776(1): p. 32-57.

171. Newman, R.A., et al., Cardiac glycosides as novel cancer therapeutic agents. Mol Interv, 2008. 8(1): p. 36-49.

172. Zhang, H., et al., Digoxin and other cardiac glycosides inhibit HIF-1alpha synthesis and block tumor growth. Proc Natl Acad Sci U S A, 2008. 105(50): p. 19579-86.

173. Moeller, B.J., et al., Radiation activates HIF-1 to regulate vascular radiosensitivity in tumors: role of reoxygenation, free radicals, and stress granules. Cancer Cell, 2004. 5(5): p. 429-41.

174. Unwith, S., et al., The potential role of HIF on tumour progression and dissemination. Int J Cancer, 2014.

175. Choi, Y.J., et al., HIF-1alpha modulation by topoisomerase inhibitors in non-small cell lung cancer cell lines. J Cancer Res Clin Oncol, 2009. 135(8): p. 1047-53. 
176. Beppu, K., et al., Topotecan blocks hypoxia-inducible factor-1alpha and vascular endothelial growth factor expression induced by insulin-like growth factor-I in neuroblastoma cells. Cancer Res, 2005. 65(11): p. 4775-81.

177. Rapisarda, A., et al., Identification of small molecule inhibitors of hypoxia-inducible factor 1 transcriptional activation pathway. Cancer Res, 2002. 62(15): p. 4316-24.

178. Kummar, S., et al., Multihistology, target-driven pilot trial of oral topotecan as an inhibitor of hypoxia-inducible factor-1 $\alpha$ in advanced solid tumors. Clin Cancer Res, 2011. 17(15): p. 512331.

179. Teng, C.M., et al., YC-1, a nitric oxide-independent activator of soluble guanylate cyclase, inhibits platelet-rich thrombosis in mice. Eur J Pharmacol, 1997. 320(2-3): p. 161-6.

180. Galle, J., et al., Effects of the soluble guanylyl cyclase activator, YC-1, on vascular tone, cyclic GMP levels and phosphodiesterase activity. Br J Pharmacol, 1999. 127(1): p. 195-203.

181. Yeo, E.J., et al., YC-1: a potential anticancer drug targeting hypoxia-inducible factor 1. J Natl Cancer Inst, 2003. 95(7): p. 516-25.

182. Sun, H.L., et al., YC-1 inhibits HIF-1 expression in prostate cancer cells: contribution of Akt/NFkappaB signaling to HIF-1alpha accumulation during hypoxia. Oncogene, 2007. 26(27): p. 3941-51.

183. Jung, Y.J., et al., IL-1beta-mediated up-regulation of HIF-1alpha via an NFkappaB/COX-2 pathway identifies HIF-1 as a critical link between inflammation and oncogenesis. FASEB J, 2003. 17(14): p. 2115-7.

184. Subbiah, V., J.C. Trent, and R. Kurzrock, Resistance to mammalian target of rapamycin inhibitor therapy in perivascular epithelioid cell tumors. J Clin Oncol, 2010. 28(24): p. e415.

185. Dancey, J.E., R. Curiel, and J. Purvis, Evaluating temsirolimus activity in multiple tumors: a review of clinical trials. Semin Oncol, 2009. 36 Suppl 3: p. S46-58.

186. Del Bufalo, D., et al., Antiangiogenic potential of the Mammalian target of rapamycin inhibitor temsirolimus. Cancer Res, 2006. 66(11): p. 5549-54.

187. Wangpaichitr, M., et al., Intrinsically lower AKT, mammalian target of rapamycin, and hypoxia-inducible factor activity correlates with increased sensitivity to 2-deoxy-D-glucose under hypoxia in lung cancer cell lines. Mol Cancer Ther, 2008. 7(6): p. 1506-13.

188. Miyazawa, M., et al., Therapeutic strategy targeting the mTOR-HIF-1alpha-VEGF pathway in ovarian clear cell adenocarcinoma. Pathol Int, 2009. 59(1): p. 19-27.

189. Majumder, P.K., et al., mTOR inhibition reverses Akt-dependent prostate intraepithelial neoplasia through regulation of apoptotic and HIF-1-dependent pathways. Nat Med, 2004. 10(6): p. 594-601.

190. Falchook, G.S., et al., Targeting hypoxia-inducible factor-1alpha (HIF-1alpha) in combination with antiangiogenic therapy: a phase I trial of bortezomib plus bevacizumab. Oncotarget, 2014. 5(21): p. 10280-92.

191. Kaluz, S., M. Kaluzova, and E.J. Stanbridge, Proteasomal inhibition attenuates transcriptional activity of hypoxia-inducible factor 1 (HIF-1) via specific effect on the HIF-1alpha C-terminal activation domain. Mol Cell Biol, 2006. 26(15): p. 5895-907. 
Click here to download high resolution image

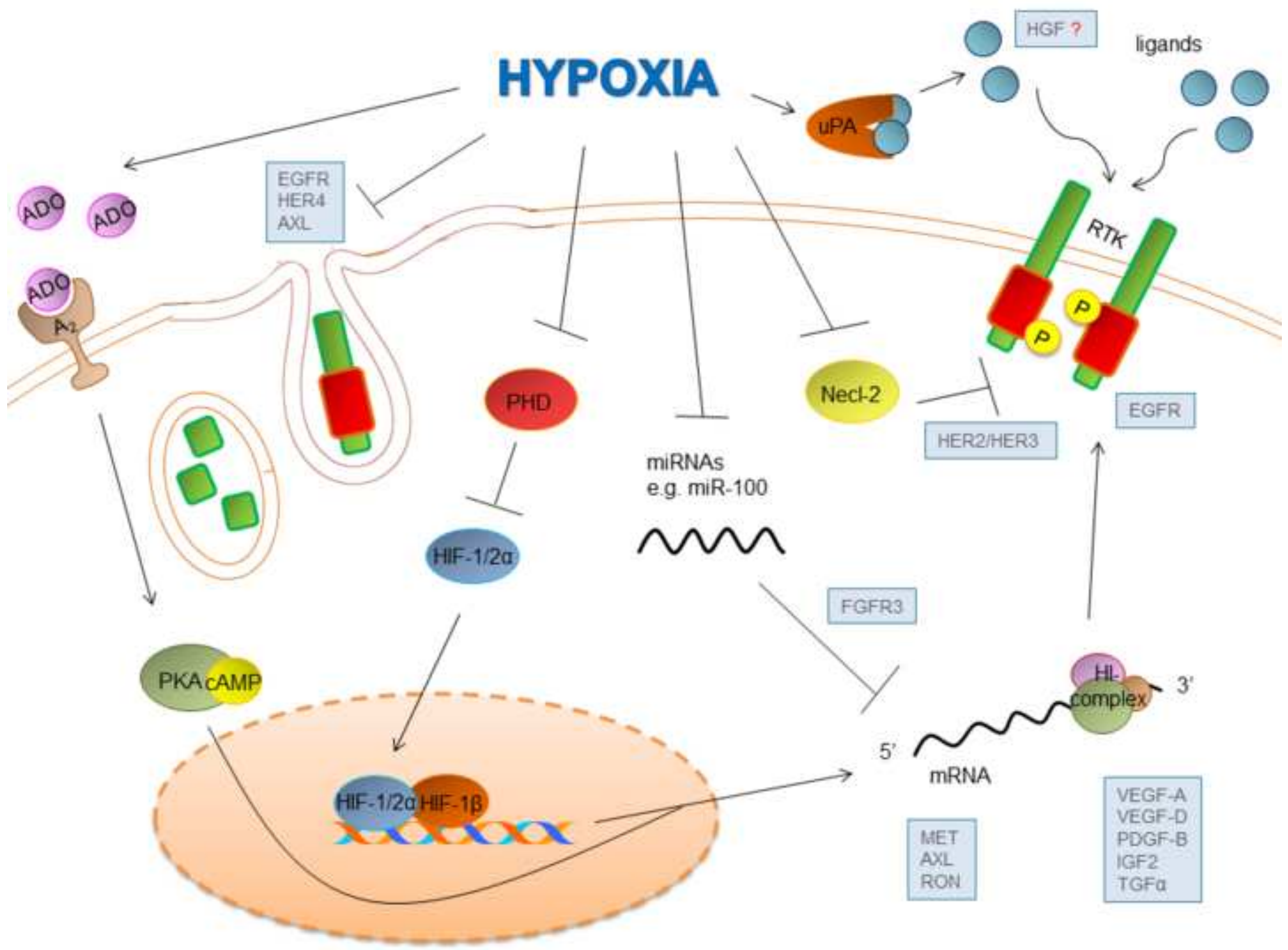


Click here to download high resolution image

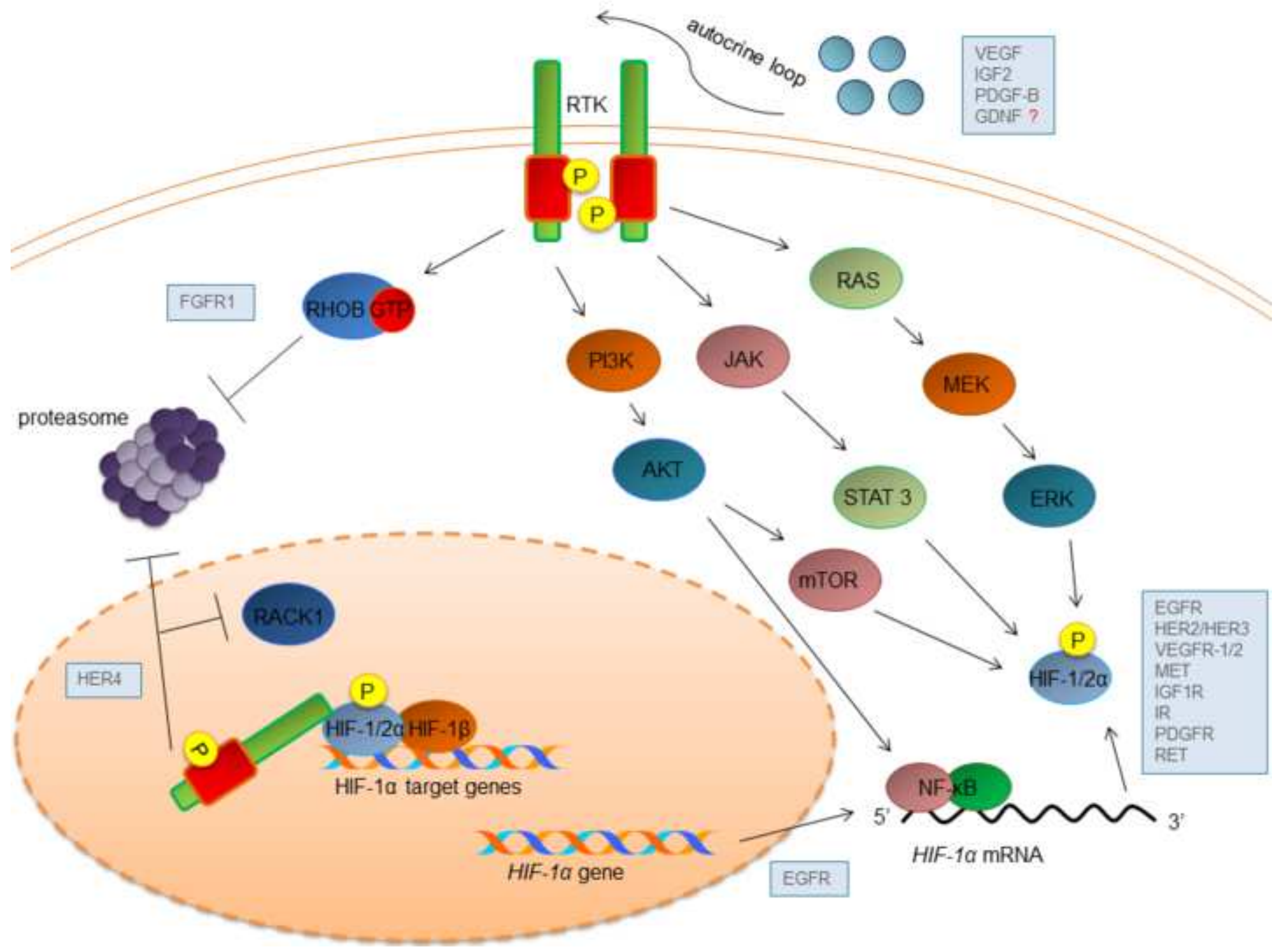

